\title{
Novel $N$-Heterocyclic Carbene Silver(I) Complexes: Synthesis, Structural Characterization, Antimicrobial and Cytotoxicity Potential Studies
}

\author{
Ichraf Slimani, ${ }^{a}$ Ahlem Chakchouk-Mtibaa, ${ }^{b}$ Lotfi Mellouli, ${ }^{b}$ Lamjed Mansour, ${ }^{c}$ \\ Ismail Ozdemir, ${ }^{d}$ Nevin Gürbü̈ ${ }^{d}$ and Naceur Hamdi ${ }^{\circledR} * a$
}

\author{
${ }^{a}$ Research Laboratory of Environmental Sciences and Technologies (LR16ESO9), \\ Higher Institute of Environmental Sciences and Technology, University of Carthage, \\ BP 77-1054 Hammam-Lif, Tunisia
}

${ }^{b}$ Laboratory of Microorganisms and Biomolecules, Center of Biotechnology of Sfax, Road of Sidi Mansour, km 6, P.O. Box 1117, 3018 Sfax, Tunisia

\author{
'Zoology Department, College of Science, King Saud University, P.O. Box 2455, 11451 Riyadh, \\ Saudi Arabia \\ ${ }^{d}$ Department of Chemistry, Faculty of Science and Art, Inönü University, \\ 44000 Malatya, Turkey
}

\begin{abstract}
In this study, a series of unsymmetrical $N, N$-disubstituted benzimidazolium salts were synthesized as $N$-heterocyclic carbene (NHC) (2a-2j) and their $\mathrm{Ag}^{\mathrm{I}}$ complexes. Their structures were characterized by elemental analyses, ${ }^{1} \mathrm{H}$ and ${ }^{13} \mathrm{C}$ nuclear magnetic resonance (NMR) and infrared (IR) spectroscopy techniques. Further, both the salts and their silver(I)-NHC complexes have been evaluated for their potential antibacterial properties against a panel of bacterial strains namely, Micrococcus luteus, Listeria monocytogenes, Salmonella Typhimurium, Staphylococcus aureus and Pseudomonas aeruginosa. The results show that silver complexes are effective against Salmonella Typhimurium, Listeria monocytogenes, and Micrococcus luteus with moderate to high activity, and their minimum inhibitory concentrations ranging from 0.0034 to $1.26 \mathrm{mg} \mathrm{mL}^{-1}$. In addition, the benzimidazoles salts $\mathbf{2} \mathbf{a}-\mathbf{2} \mathbf{j}$ and silver-NHC complexes $\mathbf{3} \mathbf{a}-\mathbf{3} \mathbf{j}$ were screened for their antitumor activity. Complex $\mathbf{3 e}$ exhibited the highest antitumor effect with half-maximal inhibitory concentration $\left(\mathrm{IC}_{50}\right)$ value of $4.2 \mu \mathrm{g} \mathrm{mL} \mathrm{m}^{-1}$ against MCF-7.
\end{abstract}

Keywords: $N$-heterocyclic carbene, benzimidazolium salts, silver(I)-NHC complexes, antimicrobial and antitumor activities

\section{Introduction}

Organometallic complexes have an important role as design of therapeutic agents in biomedical applications. Organometallic compounds with $N$-heterocyclic carbene (NHC) ligands have been used in organic transformations and metal-based drugs lately., ${ }^{1,2}$ The performance of organometallic compound in medical applications may closely be related to the choice of convenient ligands, and is crucially dependent on the respective trace metal binding forms. ${ }^{3}$ Heterocyclic azoles, such as imidazole, triazole, and especially benzimidazole have significant biological activities. ${ }^{4-7}$ Especially, NHC derived from the imidazole or benzimidazole core have considerable antibacterial or

*e-mail: naceur.hamdi@isste.rnu.tn anticancer activities.$^{8-13} \mathrm{NHCs}$ are also a well-known class of organometallic ligands which are a strong $\sigma$-donating and weak $\pi$-accepting when connected with metal ions. Metal-NHC complexes have exhibited an interesting propensity to bind deoxyribonucleic acid (DNA) by means of non-covalent interactions, which is believed to partially mediate their anti-proliferative activity, and to cleave DNA strands. ${ }^{14-17}$ In addition to their antimicrobial and anticancer activity, metal-NHC complexes have also been intensely investigated due to their noteworthy applications in catalysis. ${ }^{18-21}$ Silver has lower toxicity as compared to other transition metals. One reason for this could be the slower rate of release of silver ions, from the organometallic complexes, which also enhanced their biological activity. Among the many developed anticancer agents consisting of organometallic compounds, those based on silver-NHC 
complexes have attracted much attention because of their biological properties such as antimicrobial, anticancer, and antibacterial activities. ${ }^{22-27} \mathrm{Ag}-\mathrm{NHC}$ complexes have been suggested as antimicrobial agents to prevent infections, in wound care antiseptics and in water purification. ${ }^{28,29}$ Metallic silver was used as a treatment for gonorrhea before the development of antibiotics, while silver nitrate was commonly used as an antimicrobial compound before the discovery of penicillin in ancient times. ${ }^{30}$ Silver nitrate is still being used as a preventive drug against the development of neonatal conjunctivitis in infants. The aim of this study was to design novel $\mathrm{NHC}$ salts and their $\mathrm{Ag}^{\mathrm{I}}$ complexes and investigate their antimicrobial and cytotoxic activities. All salts and complexes structures were characterized by elemental analysis, Fourier transform infrared (FTIR), ${ }^{1} \mathrm{H}$ and ${ }^{13} \mathrm{C}$ nuclear magnetic resonance (NMR) spectroscopies.

\section{Experimental}

\section{Materials and methods}

All procedures were carried out under an inert atmosphere using standard Schlenk line techniques. Chemicals and solvents were purchased from SigmaAldrich (Istanbul, Turkey). The solvents used were purified and dried by MBraun SPS 800 solvent purification system. Column chromatography was performed by using silica gel 60 (70-230 mesh). ${ }^{1} \mathrm{H}$ and ${ }^{13} \mathrm{C}$ NMR spectra were recorded at $400 \mathrm{MHz}\left({ }^{1} \mathrm{H}\right), 100 \mathrm{MHz}\left({ }^{13} \mathrm{C}\right)$ in $\mathrm{CDCl}_{3}$ with tetramethylsilane as an internal reference. The NMR studies were carried out in high-quality $5 \mathrm{~mm}$ NMR tubes. Signals are quoted in parts per million as $\delta$ downfield from tetramethylsilane $(\delta=0.00)$ as an internal standard. NMR multiplicities are abbreviated as follows: $\mathrm{s}=$ singlet, $\mathrm{d}=$ doublet, $\mathrm{t}=$ triplet, $\mathrm{m}=$ multiplet. Gas chromatography (GC) analyses of reactions mixtures were done using a Shimadzu GC 2010-Plus GCFID system. Column: TeknokromaTRB-5 capillary column, $30 \mathrm{~m} \times 0.32 \mathrm{~mm} \times 0.25 \mu \mathrm{m}$. Initial temperature at $50{ }^{\circ} \mathrm{C}$, held for $1 \mathrm{~min}$, ramp $2{ }^{\circ} \mathrm{C} \mathrm{min}{ }^{-1}$ until $90{ }^{\circ} \mathrm{C}$, held for 3 min, ramp $40{ }^{\circ} \mathrm{C} \mathrm{min}{ }^{-1}$ until $240{ }^{\circ} \mathrm{C}$, held for $10 \mathrm{~min}$. The temperature of the injector and detector were held at $240{ }^{\circ} \mathrm{C}$. Melting points (mp) were determined with Kofler bench at Isste of Borj Cedria (Hammam-Lif, University of Carthage, Borj Cedria, Tunisia).

General procedure for the preparation of benzimidazolium salts

The benzimidazolium salts $\mathbf{2} \mathbf{a}-\mathbf{2} \mathbf{j}$ were prepared by reacting $N$-(isobutyl)-benzimidazole (1 mmol) (1) with various alkyl chloride $(1.1 \mathrm{mmol})$ in dimethylformamide (DMF; $5 \mathrm{~mL}$ ) at $80^{\circ} \mathrm{C}$ and the resulting mixture was stirred for $24 \mathrm{~h}$. Diethyl ether ( $15 \mathrm{~mL}$ ) was added to obtain a white crystalline solid, which was subsequently filtered off. The solid was washed with diethyl ether $(3 \times 10 \mathrm{~mL})$, dried under vacuum, and the crude product was recrystallized from dichloromethane/diethyl ether (1:3 ratio).

1-(Isobutyl)-3-(3,4,5-trimethoxylbenzyl)benzimidazolium chloride (2a)

Yield: $93 \%$; mp $136.2{ }^{\circ} \mathrm{C}$; IR (KBr) $v / \mathrm{cm}^{-1} 1437$; ${ }^{1} \mathrm{H}$ NMR (400 MHz, $\left.\mathrm{CDCl}_{3}\right) \delta 1.01\left(\mathrm{~d}, 6 \mathrm{H}, \mathrm{CH}_{3 \mathrm{a}, \mathrm{b}}\right), 2.39$ (hept, 1H, $\mathrm{H}_{2}, J 4 \mathrm{~Hz}$ ), 3.78 (s, 6H, $\mathrm{CH}_{3 \mathrm{c}, \mathrm{e}}$ ), 3.84 (s, 3H, $\mathrm{CH}_{3 \mathrm{~d}}$ ), 4.40 (d, 2H, H$\left., \mathrm{H}_{1}, J 4 \mathrm{~Hz}\right), 5.81$ (s, 2H, $\mathrm{H}_{1}$ ) $), 6.88$ (s, $\left.2 \mathrm{H}, \mathrm{H}_{3^{\prime \prime}, 7^{\prime}}\right), 7.57-7.74\left(\mathrm{~m}, 4 \mathrm{H}, \mathrm{H}_{4,5,6,7}\right), 12.02$ (s, 1H, $\mathrm{H}_{2}$ ); ${ }^{13} \mathrm{C} \mathrm{NMR}\left(100 \mathrm{MHz}, \mathrm{CDCl}_{3}\right) \delta 19.9\left(\mathrm{C}_{\mathrm{a}, \mathrm{b}}\right), 28.9\left(\mathrm{C}_{2}\right), 51.6$ $\left(\mathrm{C}_{1}{ }^{\prime}\right), 54.5\left(\mathrm{C}_{1}\right), 56.7\left(\mathrm{C}_{\mathrm{c}, \mathrm{e}}\right), 60.9\left(\mathrm{C}_{\mathrm{d}}\right), 106.1\left(\mathrm{C}_{3^{\prime \prime}, 7}\right), 113.2$ $\left(\mathrm{C}_{4}\right), 113.8\left(\mathrm{C}_{7}\right), 127.2\left(\mathrm{C}_{5}\right), 128.6\left(\mathrm{C}_{6}\right), 131.2\left(\mathrm{C}_{8}\right), 131.7$ $\left(\mathrm{C}_{9}\right), 138.6\left(\mathrm{C}_{5^{\prime \prime}}\right), 144.1\left(\mathrm{C}_{2,2^{\prime \prime}}\right), 153.9\left(\mathrm{C}_{4^{\prime \prime}, 6^{\prime \prime}}\right)$.

1-(Isobutyl)-3-(3,4,5-trimethoxylbenzyl)-5,6-dimethylbenzimidazolium chloride $\mathbf{( 2 b )}$

Yield: $92 \%$; mp $198.2{ }^{\circ} \mathrm{C}$; IR (KBr) $v / \mathrm{cm}^{-1} 1438$; ${ }^{1} \mathrm{H} \mathrm{NMR}\left(400 \mathrm{MHz}, \mathrm{CDCl}_{3}\right) \delta 0.98\left(\mathrm{~d}, 6 \mathrm{H}, \mathrm{CH}_{3 \mathrm{a}, \mathrm{b}}, J 8 \mathrm{~Hz}\right)$, 2.34 (hept, $1 \mathrm{H}, \mathrm{H}_{2}, J 8 \mathrm{~Hz}$ ), 2.37 (d, 6H, $\mathrm{CH}_{3 \mathrm{c}, \mathrm{d}}, J 4 \mathrm{~Hz}$ ), 3.75 (s, 3H, $\left.\mathrm{CH}_{3 \mathrm{f}}\right), 3.81$ (s, 6H, $\left.\mathrm{CH}_{3 \mathrm{e}, \mathrm{g}}\right), 4.30$ (d, 2H, $\mathrm{H}_{1}$, $J 8 \mathrm{~Hz}), 5.71\left(\mathrm{~s}, 2 \mathrm{H}, \mathrm{H}_{1}\right.$ ) $), 6.82\left(\mathrm{~s}, 2 \mathrm{H}, \mathrm{H}_{3}, 7^{\prime}\right), 7.35$ (s, 1H, $\left.\mathrm{H}_{4}\right), 7.42$ (s, $\left.1 \mathrm{H}, \mathrm{H}_{7}\right), 11.80\left(\mathrm{~s}, 1 \mathrm{H}, \mathrm{H}_{2}\right) ;{ }^{13} \mathrm{C} \mathrm{NMR}(100 \mathrm{MHz}$, $\left.\mathrm{CDCl}_{3}\right) \delta 19.7\left(\mathrm{C}_{\mathrm{c}, \mathrm{d}}\right), 20.7\left(\mathrm{C}_{\mathrm{a}, \mathrm{b}}\right), 28.7\left(\mathrm{C}_{2},\right), 51.2\left(\mathrm{C}_{1},{ }^{\prime}\right), 54.3$ $\left(\mathrm{C}_{1}\right), 56.6\left(\mathrm{C}_{\mathrm{e}, \mathrm{g}}\right), 60.8\left(\mathrm{C}_{\mathrm{f}}\right), 105.9\left(\mathrm{C}_{3^{\prime \prime}, 7^{\prime \prime}}\right), 112.8\left(\mathrm{C}_{4}\right), 113.4$ $\left(\mathrm{C}_{7}\right), 128.8,\left(\mathrm{C}_{2},\right), 129.65\left(\mathrm{C}_{8}\right), 130.1\left(\mathrm{C}_{9}\right), 137.3\left(\mathrm{C}_{5,6}\right)$, $138.4\left(\mathrm{C}_{5},\right), 142.7\left(\mathrm{C}_{2}\right), 153.7\left(\mathrm{C}_{4^{\prime \prime}, 6^{\prime}}\right)$.

1-(Isobutyl)-3-(4-tert-butylbenzyl)benzimidazolium chloride (2c)

Yield: $97 \%$; mp $217.2{ }^{\circ} \mathrm{C}$; IR (KBr) $v / \mathrm{cm}^{-1}$ 1542; ${ }^{1} \mathrm{H} \mathrm{NMR}\left(400 \mathrm{MHz}, \mathrm{CDCl}_{3}\right) \delta 1.03\left(\mathrm{~d}, 6 \mathrm{H}, \mathrm{CH}_{3 \mathrm{a}, \mathrm{b}}\right.$ ), 1.23 (s, $\left.9 \mathrm{H}, \mathrm{CH}_{3 \mathrm{c}, \mathrm{d}, \mathrm{e}}\right), 2.44$ (hept, $\left.1 \mathrm{H}, \mathrm{H}_{2}, J 8 \mathrm{~Hz}\right), 4.40$ (d, 2H, $\mathrm{H}_{1}$,

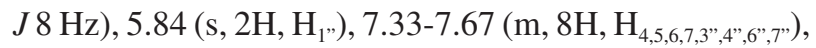
$12.0\left(\mathrm{~s}, 1 \mathrm{H}, \mathrm{H}_{2}\right) ;{ }^{13} \mathrm{C} \mathrm{NMR}\left(100 \mathrm{MHz}, \mathrm{CDCl}_{3}\right) \delta 19.3\left(\mathrm{C}_{\mathrm{a}, \mathrm{b}}\right)$, $28.6\left(\mathrm{C}_{2}\right), 30.9\left(\mathrm{C}_{\mathrm{c}, \mathrm{d}, \mathrm{e}}\right), 34.4\left(\mathrm{C}_{8^{\prime \prime}}\right), 51.8\left(\mathrm{C}_{1}{ }^{\prime}\right), 54.1\left(\mathrm{C}_{1}\right)$, $112.8\left(\mathrm{C}_{4}\right), 113.6\left(\mathrm{C}_{7}\right), 126.0\left(\mathrm{C}_{4^{\prime \prime}, 6^{\prime}}\right), 126.7\left(\mathrm{C}_{5}\right), 126.8\left(\mathrm{C}_{6}\right)$, $127.7\left(\mathrm{C}_{3^{\prime \prime}, 7}\right), 129.6\left(\mathrm{C}_{2,}\right), 130.9\left(\mathrm{C}_{8}\right), 131.5\left(\mathrm{C}_{9}\right), 143.7$ $\left(\mathrm{C}_{2}\right), 152.0\left(\mathrm{C}_{5},\right)$.

1 -(|sobutyl)-3-(4-tert-butylbenzyl)-5,6-dimethylbenzimidazolium chloride $(\mathbf{2 d})$

Yield: $98 \%$; mp $243.2{ }^{\circ} \mathrm{C}$; IR (KBr) $v / \mathrm{cm}^{-1} 1558$; ${ }^{1} \mathrm{H} \mathrm{NMR}\left(400 \mathrm{MHz}, \mathrm{CDCl}_{3}\right) \delta 1.01\left(\mathrm{~d}, 6 \mathrm{H}, \mathrm{CH}_{3 \mathrm{a}, \mathrm{b}}, J 8 \mathrm{~Hz}\right)$, $1.23\left(\mathrm{~s}, 9 \mathrm{H}, \mathrm{CH}_{3 \mathrm{c}, \mathrm{d}, \mathrm{e}}\right), 2.36\left(\mathrm{~s}, 3 \mathrm{H}, \mathrm{CH}_{3 \mathrm{c}}\right), 2.39$ (s, 3H, $\mathrm{CH}_{3 \mathrm{~d}}$ ), 2.52 (hept, $\left.1 \mathrm{H}, \mathrm{H}_{2}, J 8 \mathrm{~Hz}\right), 4.32$ (d, 2H, $\left.\mathrm{H}_{1}, J 8 \mathrm{~Hz}\right), 5.76$ 
(s, 2H, $\mathrm{H}_{\mathrm{1}^{\prime \prime}}$ ), 7.32-7.39 (m, 6H, $\left.\mathrm{H}_{4,7,3^{\prime \prime}, 4^{\prime \prime}, 6^{\prime \prime}, 7^{\prime}}\right), 11.77$ (s, 1H, $\left.\mathrm{H}_{2}\right) ;{ }^{13} \mathrm{C}$ NMR $\left(100 \mathrm{MHz}, \mathrm{CDCl}_{3}\right) \delta 19.9\left(\mathrm{C}_{\mathrm{a}, \mathrm{b}}\right), 20.7\left(\mathrm{C}_{\mathrm{c}, \mathrm{d}}\right)$, $28.8\left(\mathrm{C}_{2}\right), 31.2\left(\mathrm{C}_{\mathrm{e}, \mathrm{f}, \mathrm{g}}\right), 34.7\left(\mathrm{C}_{8^{\prime \prime}}\right), 50.8\left(\mathrm{C}_{1^{\prime}}\right), 54.3\left(\mathrm{C}_{1}\right)$, $112.8\left(\mathrm{C}_{4}\right), 113.4\left(\mathrm{C}_{7}\right), 126.2\left(\mathrm{C}_{4^{\prime \prime}, 6^{\prime}}\right), 127.9\left(\mathrm{C}_{3^{\prime \prime}, 7}\right), 129.8$ $\left(\mathrm{C}_{5,6}\right), 130.2\left(\mathrm{C}_{8}\right), 130.3\left(\mathrm{C}_{9}\right), 137.2\left(\mathrm{C}_{2^{\prime \prime}}\right), 127.87\left(\mathrm{C}_{8,9}\right)$, $142.80\left(\mathrm{C}_{2}\right), 152.30\left(\mathrm{C}_{5^{\prime \prime}}\right)$.

\section{1-(Isobutyl)-3-(2,4,6-trimethylbenzyl)benzimidazolium chloride (2e)}

Yield: $94 \%$; mp $218.3{ }^{\circ} \mathrm{C}$; IR ( $\left.\mathrm{KBr}\right) \vee / \mathrm{cm}^{-1} 1469$; ${ }^{1} \mathrm{H} \mathrm{NMR}\left(400 \mathrm{MHz}, \mathrm{CDCl}_{3}\right) \delta 1.00\left(\mathrm{~d}, 6 \mathrm{H}, \mathrm{CH}_{3 \mathrm{a}, \mathrm{b}}, J 8 \mathrm{~Hz}\right)$, $2.25\left(\mathrm{~s}, 3 \mathrm{H}, \mathrm{CH}_{3 \mathrm{~d}}\right.$ ), 2.28 (s, 6H, $\mathrm{CH}_{3 \mathrm{c}, \mathrm{e}}$ ), 2.37 (hept, $1 \mathrm{H}$, $\left.\mathrm{H}_{2}, J 8 \mathrm{~Hz}\right), 4.42\left(\mathrm{~d}, 2 \mathrm{H}, \mathrm{H}_{1}, J 8 \mathrm{~Hz}\right), 5.90\left(\mathrm{~s}, 2 \mathrm{H}, \mathrm{H}_{1}\right.$, ), $6.88\left(\mathrm{~s}, 2 \mathrm{H}, \mathrm{H}_{4^{\prime \prime}, 6^{\prime}}\right), 7.10\left(\mathrm{~d}, 1 \mathrm{H}, \mathrm{H}_{4}, J 8 \mathrm{~Hz}\right), 7.37$ (t, $1 \mathrm{H}$, $\left.\mathrm{H}_{5}, J 8 \mathrm{~Hz}\right), 7.51\left(\mathrm{t}, 1 \mathrm{H}, \mathrm{H}_{6}, J 8 \mathrm{~Hz}\right), 7.64\left(\mathrm{~d}, 1 \mathrm{H}, \mathrm{H}_{7}\right.$, $J 8 \mathrm{~Hz}), 11.61\left(\mathrm{~s}, 1 \mathrm{H}, \mathrm{H}_{2}\right) ;{ }^{13} \mathrm{C} \mathrm{NMR}\left(100 \mathrm{MHz}, \mathrm{CDCl}_{3}\right)$ $\delta 19.8\left(\mathrm{C}_{\mathrm{c}, \mathrm{e}}\right), 20.3\left(\mathrm{C}_{\mathrm{a}, \mathrm{b}}\right), 21.1\left(\mathrm{C}_{\mathrm{d}}\right), 28.9\left(\mathrm{C}_{2}\right), 47.5\left(\mathrm{C}_{1}{ }^{\prime}\right)$, $54.3\left(\mathrm{C}_{1}\right), 113.1\left(\mathrm{C}_{4}\right), 114.0\left(\mathrm{C}_{7}\right), 125.2\left(\mathrm{C}_{5,6}\right), 126.9\left(\mathrm{C}_{4^{\prime \prime}}\right)$, $127.1\left(\mathrm{C}_{6^{\prime}}\right), 130.2\left(\mathrm{C}_{8}\right), 131.3\left(\mathrm{C}_{9}\right), 131.8\left(\mathrm{C}_{3^{\prime \prime}}\right), 137.9$ $\left(\mathrm{C}_{5^{\prime \prime}, 7^{\prime}}\right), 139.6\left(\mathrm{C}_{2^{\prime \prime}}\right), 144.2\left(\mathrm{C}_{2}\right)$.

1 -(|sobutyl)-3-(4-methylbenzyl)-5,6-dimethylbenzimidazolium chloride (2f)

Yield: $93 \%$; mp $223.2{ }^{\circ} \mathrm{C}$; IR ( $\left.\mathrm{KBr}\right) \mathrm{v} / \mathrm{cm}^{-1} 1561$; ${ }^{1} \mathrm{H} \mathrm{NMR}\left(400 \mathrm{MHz}, \mathrm{CDCl}_{3}\right) \delta 1.02\left(\mathrm{~d}, 6 \mathrm{H}, \mathrm{CH}_{3 \mathrm{a}, \mathrm{b}}, J 8 \mathrm{~Hz}\right)$, 2.27 (s, 3H, $\mathrm{CH}_{3 \mathrm{e}}$ ), 2.34 (s, $3 \mathrm{H}, \mathrm{CH}_{3 \mathrm{c}}$ ), 2.35 (hept, $1 \mathrm{H}, \mathrm{H}_{2}$, $J 4 \mathrm{~Hz}$ ), 2.38 (s, 3H, $\mathrm{CH}_{3 \mathrm{~d}}$ ), $4.31\left(\mathrm{~d}, 2 \mathrm{H}, \mathrm{H}_{1}, J 8 \mathrm{~Hz}\right), 5.70$ (s, 2H, $\mathrm{H}_{1^{\prime}}$ ), $7.11\left(\mathrm{~d}, 2 \mathrm{H}, \mathrm{H}_{5,6}, J 8 \mathrm{~Hz}\right), 7.30-7.35(\mathrm{~m}, 2 \mathrm{H}$, $\left.\mathrm{H}_{3^{\prime \prime}, 4^{\prime \prime}, 6^{\prime \prime}, 7^{\prime}}\right), 11.79$ (s, 1H, $\left.\mathrm{H}_{2}\right) ;{ }^{13} \mathrm{C}$ NMR (100 MHz, $\mathrm{CDCl}_{3}$ ) $\delta 19.8\left(\mathrm{C}_{\mathrm{a}, \mathrm{b}}\right), 20.7\left(\mathrm{C}_{\mathrm{c}, \mathrm{d}}\right), 21.2\left(\mathrm{C}_{\mathrm{e}}\right), 28.8\left(\mathrm{C}_{2}\right), 50.9\left(\mathrm{C}_{1^{\prime}}\right)$, $54.2\left(\mathrm{C}_{1}\right), 112.8\left(\mathrm{C}_{4}\right), 113.4\left(\mathrm{C}_{7}\right), 128.18\left(\mathrm{C}_{5,6}\right), 129.7\left(\mathrm{C}_{5^{\prime \prime}}\right)$, $129.9\left(\mathrm{C}_{3^{\prime \prime}, 7^{\prime}}\right), 130.2\left(\mathrm{C}_{4^{\prime \prime}, 6^{\prime \prime}}\right), 130.2\left(\mathrm{C}_{8}\right), 137.2\left(\mathrm{C}_{9}\right), 139.0$ $\left(\mathrm{C}_{2^{\prime}}\right), 142.8\left(\mathrm{C}_{2}\right)$.

1-(Isobutyl)-3-(naphthyl)benzimidazolium chloride (2g)

Yield: $89 \%$; mp $146.4{ }^{\circ} \mathrm{C}$; IR (KBr) v / $\mathrm{cm}^{-1} 1665$; ${ }^{1} \mathrm{H}$ NMR $\left(400 \mathrm{MHz}, \mathrm{CDCl}_{3}\right) \delta 1.04\left(\mathrm{~d}, 6 \mathrm{H}, \mathrm{CH}_{3 \mathrm{a}, \mathrm{b}}, J 8 \mathrm{~Hz}\right)$, 2.42 (hept, 1H, $\mathrm{H}_{2}, J 8 \mathrm{~Hz}$ ), 4.41 (d, 2H, $\mathrm{H}_{1}, J 8 \mathrm{~Hz}$ ), 6.08

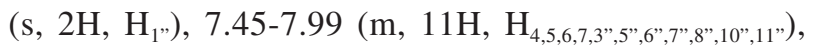
$12.15\left(\mathrm{~s}, 1 \mathrm{H}, \mathrm{H}_{2}\right) ;{ }^{13} \mathrm{C}$ NMR $\left(100 \mathrm{MHz}, \mathrm{CDCl}_{3}\right) \delta 19.9$ $\left(\mathrm{C}_{\mathrm{a}, \mathrm{b}}\right), 28.9\left(\mathrm{C}_{2}\right), 51.7\left(\mathrm{C}_{1^{\prime}}\right), 54.5\left(\mathrm{C}_{1^{\prime}}\right), 113.1\left(\mathrm{C}_{4}\right), 114.0$ $\left(\mathrm{C}_{7}\right), 125.3\left(\mathrm{C}_{7^{\prime}}\right), 126.8\left(\mathrm{C}_{5}\right), 127.0\left(\mathrm{C}_{6}\right), 127.1\left(\mathrm{C}_{3^{\prime \prime}}\right), 127.2$ $\left(\mathrm{C}_{10^{\prime}}\right), 127.8\left(\mathrm{C}_{5^{\prime \prime}}\right), 128.2\left(\mathrm{C}_{8^{\prime \prime}}\right), 129.6\left(\mathrm{C}_{6^{\prime \prime}}\right), 130.4\left(\mathrm{C}_{11^{\prime \prime}}\right)$, $131.2\left(\mathrm{C}_{2^{\prime}}\right), 131.8\left(\mathrm{C}_{4^{\prime}}\right), 131.15\left(\mathrm{C}_{9^{\prime}}\right), 133.1\left(\mathrm{C}_{8}\right), 133.3$ $\left(\mathrm{C}_{9}\right), 144.15\left(\mathrm{C}_{2}\right)$.

1-(Isobutyl)-3-(anthracen-9-ylmethyl)benzimidazolium chloride (2h)

Yield: 89\%; mp $278.9^{\circ} \mathrm{C}$; IR (KBr) $v / \mathrm{cm}^{-1} 1550$; ${ }^{1} \mathrm{H}$ NMR $\left(400 \mathrm{MHz}, \mathrm{CDCl}_{3}\right) \delta 1.02\left(\mathrm{~d}, 6 \mathrm{H}, \mathrm{CH}_{3 \mathrm{a}, \mathrm{b}}, J 8 \mathrm{~Hz}\right)$, 2.34 (hept, $1 \mathrm{H}, \mathrm{H}_{2}, J 8 \mathrm{~Hz}$ ), 4.37 (d, 2H, $\left.\mathrm{H}_{1}, J 4 \mathrm{~Hz}\right), 6.95$

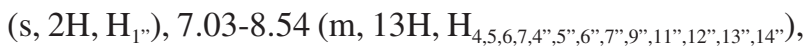
$12.27\left(\mathrm{~s}, 1 \mathrm{H}, \mathrm{H}_{2}\right) ;{ }^{13} \mathrm{C} \mathrm{NMR}\left(100 \mathrm{MHz}, \mathrm{CDCl}_{3}\right) \delta 19.8\left(\mathrm{C}_{\mathrm{a}, \mathrm{b}}\right)$, $28.8\left(\mathrm{C}_{2}\right), 45.6\left(\mathrm{C}_{1^{\prime}}\right), 54.4\left(\mathrm{C}_{1}\right), 112.8\left(\mathrm{C}_{4}\right), 114.4\left(\mathrm{C}_{7}\right)$, $121.8\left(\mathrm{C}_{9^{\prime \prime}}\right), 123.0\left(\mathrm{C}_{6^{\prime \prime}, 12^{\prime \prime}}\right), 125.5\left(\mathrm{C}_{5^{\prime \prime}, 13^{\prime}}\right), 126.6\left(\mathrm{C}_{5}\right), 126.8$ $\left(\mathrm{C}_{6}\right), 128.3\left(\mathrm{C}_{4^{\prime \prime}, 14^{\prime \prime}}\right), 129.8\left(\mathrm{C}_{7^{\prime \prime}, 11^{\prime \prime}}\right), 130.7\left(\mathrm{C}_{4^{\prime \prime}, 15^{\prime \prime}}\right), 131.0$ $\left(\mathrm{C}_{8,9}\right), 131.3\left(\mathrm{C}_{8^{\prime \prime}, 10^{\prime}}\right), 131.4\left(\mathrm{C}_{10^{\prime \prime}}\right), 131.7\left(\mathrm{C}_{2^{\prime \prime}}\right), 144.5\left(\mathrm{C}_{2}\right)$.

1-(Isobutyl)-3-(methoxyethyl)benzimidazolium chloride (2i)

Yield: $77 \%$; mp $108.5{ }^{\circ} \mathrm{C}$; IR (KBr) $v / \mathrm{cm}^{-1} 1567$; ${ }^{1} \mathrm{H}$ NMR $\left(400 \mathrm{MHz}, \mathrm{CDCl}_{3}\right) \delta 1.01\left(\mathrm{~d}, 6 \mathrm{H}, \mathrm{CH}_{3 \mathrm{a}, \mathrm{b}}, J 8 \mathrm{~Hz}\right)$, 2.38 (hept, $1 \mathrm{H}, \mathrm{H}_{2}, J 8 \mathrm{~Hz}$ ), 3.30 (s, 3H, $\mathrm{CH}_{3 \mathrm{c}}$ ), 3.91 (t, $\left.3 \mathrm{H}, \mathrm{H}_{2}, J 4 \mathrm{~Hz}\right), 4.38$ (d, 2H, $\left.\mathrm{H}_{1}, J 8 \mathrm{~Hz}\right), 4.87$ (t, $2 \mathrm{H}$, $\mathrm{H}_{1}$,,$\left.J 8 \mathrm{~Hz}\right), 7.58-7.84$ (m, 4H, $\left.\mathrm{H}_{4,5,6,7}\right), 11.46\left(\mathrm{~s}, 1 \mathrm{H}, \mathrm{H}_{2}\right)$; ${ }^{13} \mathrm{C}$ NMR (100 MHz, $\left.\mathrm{CDCl}_{3}\right) \delta 19.8\left(\mathrm{C}_{\mathrm{a}, \mathrm{b}}\right), 28.9\left(\mathrm{C}_{2}\right), 47.7$ $\left(\mathrm{C}_{1^{\prime}}\right), 54.3\left(\mathrm{C}_{\mathrm{c}}\right), 59.1\left(\mathrm{C}_{1^{\prime}}\right), 70.5\left(\mathrm{C}_{2^{\prime}}\right), 112.8\left(\mathrm{C}_{4}\right), 114.2\left(\mathrm{C}_{7}\right)$, $126.9\left(\mathrm{C}_{5,6}\right), 131.4\left(\mathrm{C}_{8}\right), 132.1\left(\mathrm{C}_{9}\right), 143.9\left(\mathrm{C}_{2}\right)$.

1-(Isobutyl)-3-(isobutyl)-5,6-dimethylbenzimidazolium chloride (2j)

Yield: 87\%; mp $127.9{ }^{\circ} \mathrm{C}$; IR (KBr) v / $\mathrm{cm}^{-1} 1666$; ${ }^{1} \mathrm{H}$ NMR (400 MHz, $\left.\mathrm{CDCl}_{3}\right) \delta 1.01\left(\mathrm{~d}, 12 \mathrm{H}, \mathrm{CH}_{3 \mathrm{a}, \mathrm{b}, \mathrm{c}, \mathrm{d}}\right.$, $J 4 \mathrm{~Hz}$ ), 2.39 (hept, $2 \mathrm{H}, \mathrm{H}_{2^{\prime}, 2}, J 8 \mathrm{~Hz}$ ), 2.44 (s, 6H, $\mathrm{CH}_{3 \mathrm{e}, \mathrm{f}}$ ), 4.39 (d, 4H, $\left.\mathrm{H}_{1,1},{ }^{\prime}, J 8 \mathrm{~Hz}\right), 7.41$ (s, 2H, $\left.\mathrm{H}_{4,7}\right), 11.26$ (s, $1 \mathrm{H}$, $\left.\mathrm{H}_{2}\right) ;{ }^{13} \mathrm{C}$ NMR (100 MHz, $\left.\mathrm{CDCl}_{3}\right) \delta 19.8\left(\mathrm{C}_{\mathrm{a}, \mathrm{b}, \mathrm{c}, \mathrm{d}}\right), 20.7\left(\mathrm{C}_{\mathrm{e}, \mathrm{f}}\right)$, $28.9\left(\mathrm{C}_{2^{\prime}, 2^{\prime}}\right), 54.1\left(\mathrm{C}_{1^{\prime},{ }^{\prime}}\right), 112.9\left(\mathrm{C}_{4,7}\right), 130.0\left(\mathrm{C}_{8,9}\right), 137.4$ $\left(\mathrm{C}_{5,6}\right), 142.1\left(\mathrm{C}_{2}\right)$.

General procedure for the preparation of silver(I)-NHC complexes

A solution of benzimidazolium salt $(1.0 \mathrm{mmol})$ and $\mathrm{Ag}_{2} \mathrm{O}(1.0 \mathrm{mmol})$ in dichloromethane $(15 \mathrm{~mL})$ was stirred at room temperature for $24 \mathrm{~h}$. The reaction mixture was filtered through celite and the solvent removed under reduced pressure. The crude product was recrystallized from dichloromethane/diethyl ether (1:3).

Chloro[1-(isobutyl)-3-(3,4,5-trimethoxylbenzyl) benzimidazole-2-ylidene]silver(I) (3a)

Yield: $75 \%$; mp $136.2{ }^{\circ} \mathrm{C}$; IR (KBr) v / $\mathrm{cm}^{-1} 1567$; ${ }^{1} \mathrm{H} \mathrm{NMR}\left(400 \mathrm{MHz}, \mathrm{CDCl}_{3}\right) \delta 1.00\left(\mathrm{~d}, 6 \mathrm{H}, \mathrm{CH}_{3 \mathrm{a}, \mathrm{b}}, J 4 \mathrm{~Hz}\right)$, 2.36 (hept, $1 \mathrm{H}, \mathrm{H}_{2}, J 4 \mathrm{~Hz}$ ), 3.78 (s, $6 \mathrm{H}, \mathrm{CH}_{3 \mathrm{ce},}$ ), 3.80 (s, $\left.3 \mathrm{H}, \mathrm{CH}_{3 \mathrm{~d}}\right), 4.25\left(\mathrm{~d}, 2 \mathrm{H}, \mathrm{H}_{1}, J 8 \mathrm{~Hz}\right), 5.52\left(\mathrm{~s}, 2 \mathrm{H}, \mathrm{H}_{1}\right.$ ), 6.50 (s, $\left.2 \mathrm{H}, \mathrm{H}_{3^{\prime \prime}, 7^{\prime}}\right), 7.33-7.49$ ( $\mathrm{m}, 4 \mathrm{H}, \mathrm{H}_{4,5,6,7}$ ); ${ }^{13} \mathrm{C} \mathrm{NMR}$ $\left(100 \mathrm{MHz}, \mathrm{CDCl}_{3}\right) \delta 20.3\left(\mathrm{C}_{\mathrm{a}, \mathrm{b}}\right), 29.4\left(\mathrm{C}_{2}\right), 53.5\left(\mathrm{C}_{\mathrm{l}^{\prime}}\right), 56.4$ $\left(\mathrm{C}_{\mathrm{c}, \mathrm{e}}\right), 56.9\left(\mathrm{C}_{1}\right), 61.0\left(\mathrm{C}_{\mathrm{d}}\right), 104.5\left(\mathrm{C}_{3^{\prime \prime}, 7^{\prime}}\right), 111.9\left(\mathrm{C}_{4}\right), 112.1$ $\left(\mathrm{C}_{7}\right), 124.4\left(\mathrm{C}_{5}\right), 124.5\left(\mathrm{C}_{6}\right), 130.6\left(\mathrm{C}_{2^{\prime}}\right), 133.8\left(\mathrm{C}_{8}\right), 134.2$ $\left(\mathrm{C}_{9}\right), 138.2\left(\mathrm{C}_{5^{\prime \prime}}\right), 153.8\left(\mathrm{C}_{4^{\prime \prime}, 6^{\prime}}\right)$; elemental analysis calcd. for $\mathrm{C}_{21} \mathrm{H}_{26} \mathrm{AgClN}_{2} \mathrm{O}_{3}$ : C 50.67, H 5.26, N 5.62\%, found: C 50.1, H 5.4, N 5.8\%. 
Chloro[1-(isobutyl)-3-(3,4,5-trimethoxylbenzyl)5,6-dimethylbenzimidazole-2-ylidene]silver(I) (3b)

Yield: $92 \%$; mp $289.5{ }^{\circ} \mathrm{C}$; IR (KBr) $v / \mathrm{cm}^{-1} 1583$; ${ }^{1} \mathrm{H}$ NMR $\left(400 \mathrm{MHz}, \mathrm{CDCl}_{3}\right) \delta 0.99\left(\mathrm{~d}, 6 \mathrm{H}, \mathrm{CH}_{3 \mathrm{a}, \mathrm{b}}, J 8 \mathrm{~Hz}\right)$, $2.34\left(\mathrm{~s}, 6 \mathrm{H}, \mathrm{CH}_{3 \mathrm{c}}\right), 2.35$ (hept, $1 \mathrm{H}, \mathrm{H}_{2}$ ), $2.38\left(\mathrm{~s}, 6 \mathrm{H}, \mathrm{CH}_{3 \mathrm{~d}}\right.$ ), $3.78\left(\mathrm{~s}, 6 \mathrm{H}, \mathrm{CH}_{3 \mathrm{e}, \mathrm{g}}\right), 3.81\left(\mathrm{~s}, 3 \mathrm{H}, \mathrm{CH}_{3 \mathrm{f}}\right), 4.18\left(\mathrm{~d}, 2 \mathrm{H}, \mathrm{H}_{1}\right.$, $J 8 \mathrm{~Hz}$ ), 5.45 (s, 2H, $\left.\mathrm{H}_{\mathrm{\prime}^{\prime}}\right), 6.45$ (s, 2H, $\left.\mathrm{H}_{\left.3^{\prime \prime}, 7^{\prime}\right)}\right), 7.15$ (s, $1 \mathrm{H}$, $\left.\mathrm{H}_{4}\right), 7.21\left(\mathrm{~s}, 1 \mathrm{H}, \mathrm{H}_{7}\right) ;{ }^{13} \mathrm{C} \mathrm{NMR}\left(100 \mathrm{MHz}, \mathrm{CDCl}_{3}\right) \delta 20.3$ $\left(\mathrm{C}_{\mathrm{c}, \mathrm{d}}\right), 20.5\left(\mathrm{C}_{\mathrm{a}, \mathrm{b}}\right), 29.3\left(\mathrm{C}_{2}\right), 53.3\left(\mathrm{C}_{\mathrm{l}^{\prime}}\right), 56.3\left(\mathrm{C}_{\mathrm{e}, \mathrm{g}}\right), 56.8$ $\left(\mathrm{C}_{1}\right), 61.0\left(\mathrm{C}_{\mathrm{f}}\right), 104.4\left(\mathrm{C}_{3^{\prime \prime}, 7}\right), 112.0\left(\mathrm{C}_{4}\right), 112.2\left(\mathrm{C}_{7}\right), 130.9$ $\left(\mathrm{C}_{2^{\prime \prime}}\right), 132.4\left(\mathrm{C}_{8}\right), 132.7\left(\mathrm{C}_{9}\right), 138.45\left(\mathrm{C}_{5^{\prime \prime}}\right), 133.8\left(\mathrm{C}_{5}\right)$, $133.9\left(\mathrm{C}_{6}\right), 138.1\left(\mathrm{C}_{2}\right), 153.8\left(\mathrm{C}_{4^{\prime \prime}, 6^{\prime}}\right), \mathrm{C}_{2}$-Ag: not observed; elemental analysis calcd. for $\mathrm{C}_{23} \mathrm{H}_{30} \mathrm{AgClN}_{2} \mathrm{O}_{3}$ : C 52.53, H 5.75, N 5.32\%, found: C 52.7, H 5.9, N 5.5\%.

Chloro[1-(isobutyl)-3-(4-tert-butylbenzyl)benzimidazole2-ylidene]silver (3c)

Yield: $78 \%$; mp $108.6{ }^{\circ} \mathrm{C}$; IR $(\mathrm{KBr}) \vee / \mathrm{cm}^{-1} 1450$; ${ }^{1} \mathrm{H} \mathrm{NMR}\left(400 \mathrm{MHz}, \mathrm{CDCl}_{3}\right) \delta 1.02\left(\mathrm{~d}, 6 \mathrm{H}, \mathrm{CH}_{3 \mathrm{a}, \mathrm{b}}, J 8 \mathrm{~Hz}\right)$, 1.27 (s, 9H, $\mathrm{CH}_{3 \mathrm{c}, \mathrm{d}, \mathrm{e}}$ ), 2.36 (hept, $1 \mathrm{H}, \mathrm{H}_{2}, J 8 \mathrm{~Hz}$ ), 4.24 $\left(\mathrm{d}, 2 \mathrm{H}, \mathrm{H}_{1}, J 8 \mathrm{~Hz}\right), 5.58\left(\mathrm{~s}, 2 \mathrm{H}, \mathrm{H}_{1^{\prime}}\right), 7.17-7.48(\mathrm{~m}, 8 \mathrm{H}$,

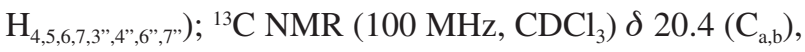
$29.4\left(\mathrm{C}_{2}\right), 31.3\left(\mathrm{C}_{\mathrm{c}, \mathrm{d}, \mathrm{e}}\right), 34.7\left(\mathrm{C}_{8^{\prime \prime}}\right), 53.1\left(\mathrm{C}_{1^{\prime}}\right), 56.9\left(\mathrm{C}_{1}\right)$, $111.7\left(\mathrm{C}_{4}\right), 112.3\left(\mathrm{C}_{7}\right), 124.2\left(\mathrm{C}_{4^{\prime}}\right), 124.3\left(\mathrm{C}_{6^{\prime}}\right), 126.1\left(\mathrm{C}_{5,6}\right)$, $126.9\left(\mathrm{C}_{3^{\prime \prime}, 7^{\prime}}\right), 131.9\left(\mathrm{C}_{2^{\prime}}\right), 133.8\left(\mathrm{C}_{8}\right), 134.3\left(\mathrm{C}_{9}\right), 151.7$ $\left(\mathrm{C}_{5^{\prime}}\right), \mathrm{C}_{2}$ - $\mathrm{Ag}$ : not observed; elemental analysis calcd. for $\mathrm{C}_{22} \mathrm{H}_{28} \mathrm{AgClN}_{2}$ : C 56.97, H 6.08, N 6.04\%, found: C 57.1, H 6.1, N 6.3\%.

Chloro[1-(isobutyl)-3-(4-tert-butylbenzyl)-5,6-dimethylbenzimidazole-2-ylidene]silver(I) (3d)

Yield: $79 \%$; mp $118.2{ }^{\circ} \mathrm{C}$; IR (KBr) v / $\mathrm{cm}^{-1} 1450$; ${ }^{1} \mathrm{H}$ NMR (400 MHz, $\left.\mathrm{CDCl}_{3}\right) \delta 1.01\left(\mathrm{~d}, 6 \mathrm{H}, \mathrm{CH}_{3 \mathrm{a}, \mathrm{b}}, J 4 \mathrm{~Hz}\right)$, 1.28 (s, 9H, $\left.\mathrm{CH}_{3 \mathrm{ccd}, \mathrm{e}}\right), 2.32$ (s, $3 \mathrm{H}, \mathrm{CH}_{3 \mathrm{c}}$ ), 2.35 (hept, $1 \mathrm{H}$, $\left.\mathrm{H}_{2}, J 8 \mathrm{~Hz}\right), 2.37$ (s, $\left.3 \mathrm{H}, \mathrm{CH}_{3 \mathrm{~d}}\right), 4.16\left(\mathrm{~d}, 2 \mathrm{H}, \mathrm{H}_{1}, J 8 \mathrm{~Hz}\right)$, $5.51\left(\mathrm{~s}, 2 \mathrm{H}, \mathrm{H}_{\mathrm{l}^{\prime}}\right), 7.12-7.34\left(\mathrm{~m}, 6 \mathrm{H}, \mathrm{H}_{\left.4,7,3^{\prime \prime}, 4^{\prime \prime}, 6^{\prime \prime}, 7^{\prime}\right)}\right){ }^{13} \mathrm{C} \mathrm{NMR}$ $\left(100 \mathrm{MHz}, \mathrm{CDCl}_{3}\right) \delta 20.4\left(\mathrm{C}_{\mathrm{c}, \mathrm{d}}\right), 20.5\left(\mathrm{C}_{\mathrm{a}}\right), 20.6\left(\mathrm{C}_{\mathrm{b}}\right), 29.3$ $\left(\mathrm{C}_{2}\right), 31.3\left(\mathrm{C}_{\mathrm{eff}, \mathrm{g}}\right), 34.7\left(\mathrm{C}_{8^{\prime}}\right), 52.9\left(\mathrm{C}_{1^{\prime}}\right), 56.8\left(\mathrm{C}_{1}\right), 111.9$ $\left(\mathrm{C}_{4}\right), 112.4\left(\mathrm{C}_{7}\right), 126.1\left(\mathrm{C}_{4^{\prime \prime}, 6^{\prime}}\right), 126.7\left(\mathrm{C}_{3^{\prime \prime}, 7^{\prime}}\right), 132.2\left(\mathrm{C}_{8,9}\right)$, $132.4\left(\mathrm{C}_{5}\right), 132.8\left(\mathrm{C}_{6}\right), 133.7\left(\mathrm{C}_{2}{ }^{\prime}\right), 133.8\left(\mathrm{C}_{2}\right), 151.5$ $\left(\mathrm{C}_{5^{\prime}}\right), \mathrm{C}_{2}$ - $\mathrm{Ag}$ : not observed; elemental analysis calcd. for $\mathrm{C}_{24} \mathrm{H}_{32} \mathrm{AgClN}_{2}$ : C 58.60, H 6.55, N 5.69\%, found: C 58.8, H 6.7, N 5.8\%.

Chloro[1-(isobutyl)-3-(2,4,6-trimethylbenzyl)benzimidazole2-ylidene]silver (3e)

Yield: $74 \%$; mp $194.2{ }^{\circ} \mathrm{C}$; IR (KBr) $v / \mathrm{cm}^{-1} 1467$; ${ }^{1} \mathrm{H}$ NMR $\left(400 \mathrm{MHz}, \mathrm{CDCl}_{3}\right) \delta 0.95\left(\mathrm{~d}, 6 \mathrm{H}, \mathrm{CH}_{3 \mathrm{a}, \mathrm{b}}, J 4 \mathrm{~Hz}\right)$, $2.23\left(\mathrm{~s}, 6 \mathrm{H}, \mathrm{CH}_{3 \mathrm{ce},}\right), 2.30$ (hept, $\left.1 \mathrm{H}, \mathrm{H}_{2}\right), 2.34\left(\mathrm{~s}, 3 \mathrm{H}, \mathrm{CH}_{3 \mathrm{~d}}\right.$ ), $4.19\left(\mathrm{~d}, 2 \mathrm{H}, \mathrm{H}_{1}, J 8 \mathrm{~Hz}\right), 5.49$ (s, 2H, $\left.\mathrm{H}_{1}{ }^{\prime}\right), 7.24-7.47$ (m, $\left.6 \mathrm{H}, \mathrm{H}_{4,5,6,7,4^{\prime \prime}, 6^{\prime}}\right) ;{ }^{13} \mathrm{C}$ NMR (100 MHz, $\left.\mathrm{CDCl}_{3}\right) \delta 20.4\left(\mathrm{C}_{\mathrm{a}, \mathrm{b}}\right)$,
$20.5\left(\mathrm{C}_{\mathrm{c}, \mathrm{e}}\right), 21.3\left(\mathrm{C}_{\mathrm{d}}\right), 29.4\left(\mathrm{C}_{2}\right), 48.0\left(\mathrm{C}_{1^{\prime}}\right), 57.4\left(\mathrm{C}_{1}\right)$, $111.7\left(\mathrm{C}_{4}\right), 111.8\left(\mathrm{C}_{7}\right), 124.1\left(\mathrm{C}_{5}\right), 124.3\left(\mathrm{C}_{6}\right), 126.7\left(\mathrm{C}_{4^{\prime \prime}, 6^{\prime}}\right)$, $130.4\left(\mathrm{C}_{5^{\prime \prime}, 2^{\prime}}\right), 134.2\left(\mathrm{C}_{8}\right), 134.3\left(\mathrm{C}_{9}\right), 137.5\left(\mathrm{C}_{3^{\prime \prime}}\right), 139.6$ $\left(\mathrm{C}_{7}\right.$ ), $\mathrm{C}_{2}$ - Ag: not observed; elemental analysis calcd. for $\mathrm{C}_{21} \mathrm{H}_{26} \mathrm{AgClN}_{2}$ : C 56.07, H 5.82, N 6.22\%, found: C 56.1, H 5.9, N 6.3\%.

Chloro[1-(isobutyl)-3-(4-methylbenzyl)-5,6-dimethylbenzimidazole-2-ylidene]silver (3f)

Yield: 93\%; mp $161.2{ }^{\circ} \mathrm{C}$; IR ( $\left.\mathrm{KBr}\right) \vee / \mathrm{cm}^{-1} 1433$; ${ }^{1} \mathrm{H} \mathrm{NMR}\left(400 \mathrm{MHz}, \mathrm{CDCl}_{3}\right) \delta 1.00\left(\mathrm{~d}, 6 \mathrm{H}, \mathrm{CH}_{3 \mathrm{a}, \mathrm{b}}, J 4 \mathrm{~Hz}\right)$, 2.31 (s, 3H, $\mathrm{CH}_{3 \mathrm{cod}}$ ), 2.35 (hept, $1 \mathrm{H}, \mathrm{H}_{2}, J 8 \mathrm{~Hz}$ ), 2.36 (s, $\left.3 \mathrm{H}, \mathrm{CH}_{3 \mathrm{e}}\right), 4.17\left(\mathrm{~d}, 2 \mathrm{H}, \mathrm{H}_{1}, J 8 \mathrm{~Hz}\right), 5.50\left(\mathrm{~s}, 2 \mathrm{H}, \mathrm{H}_{1}\right.$ ),

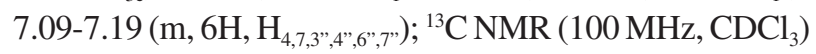
$\delta 20.4\left(\mathrm{C}_{\mathrm{c}, \mathrm{d}}\right), 20.5\left(\mathrm{C}_{\mathrm{a}}\right), 20.6\left(\mathrm{C}_{\mathrm{b}}\right), 21.2\left(\mathrm{C}_{\mathrm{e}}\right), 29.3\left(\mathrm{C}_{2}\right)$, $53.1\left(\mathrm{C}_{1^{\prime}}\right), 56.8\left(\mathrm{C}_{1}\right), 111.9\left(\mathrm{C}_{4}\right), 112.4\left(\mathrm{C}_{7}\right), 127.0\left(\mathrm{C}_{3^{\prime \prime}, 7{ }^{\prime}}\right)$, $129.8\left(\mathrm{C}_{4^{\prime \prime}, 6^{\prime \prime}}\right), 132.2\left(\mathrm{C}_{2^{\prime \prime}, 5^{\prime \prime}}\right), 133.7\left(\mathrm{C}_{8,9}\right), 133.8\left(\mathrm{C}_{5}\right), 138.3$ $\left(\mathrm{C}_{6}\right), \mathrm{C}_{2}-\mathrm{Ag}$ : not observed; elemental analysis calcd. for $\mathrm{C}_{21} \mathrm{H}_{26} \mathrm{AgClN}_{2}$ : C 56.07, H 5.82, N 6.22\%, found: C 56.1, H 5.9, N 6.3\%.

Chloro[1-(isobutyl)-3-(naphthyl)benzimidazole-2-ylidene] silver(I) (3g)

Yield: $76 \%$; mp $195.4{ }^{\circ} \mathrm{C}$; IR (KBr) v / cm ${ }^{-1} 1437$; ${ }^{1} \mathrm{H} \mathrm{NMR}\left(400 \mathrm{MHz}, \mathrm{CDCl}_{3}\right) \delta 1.02\left(\mathrm{~d}, 6 \mathrm{H}, \mathrm{CH}_{3 \mathrm{a}, \mathrm{b}}, J 8 \mathrm{~Hz}\right)$, 2.39 (hept, $1 \mathrm{H}, \mathrm{H}_{2}, J 8 \mathrm{~Hz}$ ), 4.27 (d, 2H, $\mathrm{H}_{1}, J 8 \mathrm{~Hz}$ ), 5.77

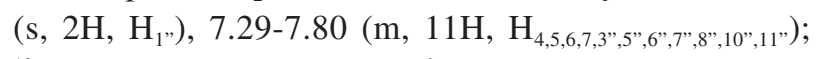
${ }^{13} \mathrm{C}$ NMR $\left(100 \mathrm{MHz}, \mathrm{CDCl}_{3}\right) \delta 20.4\left(\mathrm{C}_{\mathrm{a}, \mathrm{b}}\right), 29.5\left(\mathrm{C}_{2}\right), 53.9$ $\left(\mathrm{C}_{1^{\prime}}\right), 56.9\left(\mathrm{C}_{1}\right), 111.8\left(\mathrm{C}_{4}\right), 112.4\left(\mathrm{C}_{7}\right), 124.3\left(\mathrm{C}_{5}\right), 124.4$ $\left(\mathrm{C}_{6}\right), 124.5\left(\mathrm{C}_{7^{\prime}}\right), 126.5\left(\mathrm{C}_{6^{\prime}}\right), 126.7\left(\mathrm{C}_{3^{\prime}}\right), 126.8\left(\mathrm{C}_{10^{\prime}}\right), 127.9$ $\left(\mathrm{C}_{5^{\prime \prime}}\right), 128.0\left(\mathrm{C}_{8^{\prime \prime}}\right), 129.3\left(\mathrm{C}_{11^{\prime}}\right), 132.3\left(\mathrm{C}_{4^{\prime \prime}}\right), 133.3\left(\mathrm{C}_{9^{\prime \prime}}\right)$, $133.3\left(\mathrm{C}_{8}\right), 133.7\left(\mathrm{C}_{9}\right), 134.4\left(\mathrm{C}_{2^{\prime \prime}}\right), \mathrm{C}_{2}$ - $\mathrm{Ag}$ : not observed; elemental analysis calcd. for $\mathrm{C}_{22} \mathrm{H}_{22} \mathrm{AgClN}_{2}$ : C 57.72, H 4.84, N 6.12\%, found: C 57.9, H 4.9, N 6.3\%.

Chloro[1-(isobutyl)-3-(anthracen-9-ylmethyl)benzimidazole2-ylidene]silver(I) (3h)

Yield: $74 \%$; $\mathrm{mp} 252.3{ }^{\circ} \mathrm{C}$; IR ( $\left.\mathrm{KBr}\right) \mathrm{v} / \mathrm{cm}^{-1} 1450$; ${ }^{1} \mathrm{H} \mathrm{NMR}\left(400 \mathrm{MHz}, \mathrm{CDCl}_{3}\right) \delta 0.95\left(\mathrm{~d}, 6 \mathrm{H}, \mathrm{CH}_{3 \mathrm{a}, \mathrm{b}}, J 8 \mathrm{~Hz}\right)$, 2.29 (hept, $\left.1 \mathrm{H}, \mathrm{H}_{2}, J 8 \mathrm{~Hz}\right), 4.16\left(\mathrm{~d}, 2 \mathrm{H}, \mathrm{H}_{1}, J 8 \mathrm{~Hz}\right.$ ), 6.50 (s, 2H, $\left.\mathrm{H}_{\mathrm{1}^{\prime}}\right), 7.01-7.12\left(\mathrm{~m}, 2 \mathrm{H}, \mathrm{H}_{5^{\prime \prime}, 6^{\prime}}\right), 7.29(\mathrm{~d}, 1 \mathrm{H}$, $\left.\mathrm{H}_{4^{\prime \prime}}, J 8 \mathrm{~Hz}\right), 7.40\left(\mathrm{~d}, 1 \mathrm{H}, \mathrm{H}_{7^{\prime \prime}}, J 8 \mathrm{~Hz}\right), 7.49-7.57(\mathrm{~m}$, $\left.4 \mathrm{H}, \mathrm{H}_{4,5,6,7}\right), 8.10\left(\mathrm{~d}, 2 \mathrm{H}, \mathrm{H}_{11^{\prime \prime}, 12^{\prime}}\right), 8.23\left(\mathrm{~d}, 2 \mathrm{H}, \mathrm{H}_{13^{\prime \prime}, 14^{\prime \prime}}\right.$, $J 8 \mathrm{~Hz}), 8.64$ (s, $\left.1 \mathrm{H}, \mathrm{H}_{9,}\right) ;{ }^{13} \mathrm{C}$ NMR $\left(100 \mathrm{MHz}, \mathrm{CDCl}_{3}\right)$ $\delta 20.4\left(\mathrm{C}_{\mathrm{a}, \mathrm{b}}\right), 29.4\left(\mathrm{C}_{2}\right), 46.9\left(\mathrm{C}_{1^{\prime \prime}}\right), 57.3\left(\mathrm{C}_{1}\right), 111.7\left(\mathrm{C}_{4}\right)$, $112.3\left(\mathrm{C}_{7}\right), 123.0\left(\mathrm{C}_{5,6}\right), 123.3\left(\mathrm{C}_{9^{\prime}}\right), 124.2\left(\mathrm{C}_{6^{\prime \prime}, 12^{\prime \prime}}\right), 125.4$ $\left(\mathrm{C}_{5^{\prime \prime}, 13^{\prime \prime}}\right), 127.8\left(\mathrm{C}_{4^{\prime \prime}, 14^{\prime \prime}, 7^{\prime \prime}, 11^{\prime \prime}}\right), 130.1\left(\mathrm{C}_{3^{\prime \prime}, 15^{\prime \prime}}\right), 130.5\left(\mathrm{C}_{8^{\prime \prime}, 10^{\prime \prime}}\right)$, $131.2\left(\mathrm{C}_{8,9}\right), 131.6\left(\mathrm{C}_{2^{\prime}}\right), \mathrm{C}_{2}-\mathrm{Ag}$ : not observed; elemental analysis calcd. for $\mathrm{C}_{26} \mathrm{H}_{24} \mathrm{AgClN}_{2}$ : C 61.49, $\mathrm{H} \mathrm{4.76,}$ N 5.51\%, found: C 61.6, H 4.9, N 5.8\%. 
Chloro[1-(isobutyl)-3-(methoxyethyl)benzimidazole2-ylidene]silver(I) (3i)

Yield: $77 \%$; mp $188.5{ }^{\circ} \mathrm{C}$; IR ( $\left.\mathrm{KBr}\right) \mathrm{v} / \mathrm{cm}^{-1} 1433$; ${ }^{1} \mathrm{H}$ NMR $\left(400 \mathrm{MHz}, \mathrm{CDCl}_{3}\right) \delta 0.99\left(\mathrm{~d}, 6 \mathrm{H}, \mathrm{CH}_{3 \mathrm{a}, \mathrm{b}}, J 4 \mathrm{~Hz}\right)$, 2.33 (hept, $1 \mathrm{H}, \mathrm{H}_{2}, J 4 \mathrm{~Hz}$ ), 3.29 (s, $3 \mathrm{H}, \mathrm{CH}_{3 \mathrm{c}}$ ), 3.79 (t, $\left.3 \mathrm{H}, \mathrm{H}_{2},, J 4 \mathrm{~Hz}\right), 4.20\left(\mathrm{~d}, 2 \mathrm{H}, \mathrm{H}_{1},, J 8 \mathrm{~Hz}\right), 4.56\left(\mathrm{t}, 2 \mathrm{H}, \mathrm{H}_{1}\right.$, $J 8 \mathrm{~Hz}), 7.37-7.59\left(\mathrm{~m}, 4 \mathrm{H}, \mathrm{H}_{4,5,6,7}\right) ;{ }^{13} \mathrm{C} \mathrm{NMR}(100 \mathrm{MHz}$, $\left.\mathrm{CDCl}_{3}\right) \delta 20.4\left(\mathrm{C}_{\mathrm{a}, \mathrm{b}}\right), 29.4\left(\mathrm{C}_{2}\right), 49.5\left(\mathrm{C}_{1^{\prime}}\right), 56.9\left(\mathrm{C}_{\mathrm{c}}\right), 59.2$ $\left(\mathrm{C}_{1}\right), 72.0\left(\mathrm{C}_{2^{\prime}}\right), 111.5\left(\mathrm{C}_{4}\right), 112.4\left(\mathrm{C}_{7}\right), 124.1\left(\mathrm{C}_{5,6}\right), 133.9$ $\left(\mathrm{C}_{8}\right), 134.5\left(\mathrm{C}_{9}\right), \mathrm{C}_{2}-\mathrm{Ag}$ : not observed; elemental analysis calcd. for $\mathrm{C}_{14} \mathrm{H}_{20} \mathrm{AgClN}_{2} \mathrm{O}$ : C 44.76, H 5.36, N 7.45\%, found: C 44.8, H 5.5, N 7.6\%.

\section{Chloro[1-(isobutyl)-3-(isobutyl)-5,6-dimethylbenzimidazole-} 2-ylidene]silver(I) (3j)

Yield: $72 \%$; mp $168.9^{\circ} \mathrm{C}$; IR (KBr) v / $\mathrm{cm}^{-1} 1600$; ${ }^{1} \mathrm{H}$ NMR $\left(400 \mathrm{MHz}, \mathrm{CDCl}_{3}\right) \delta 0.97\left(\mathrm{~d}, 12 \mathrm{H}, \mathrm{CH}_{3 \mathrm{a}, \mathrm{b}, \mathrm{c}, \mathrm{d}}\right.$, $J 8 \mathrm{~Hz}$ ), 2.33 (hept, $2 \mathrm{H}, \mathrm{H}_{2,2},{ }^{\prime}, J 8 \mathrm{~Hz}$ ), 2.38 (s, $6 \mathrm{H}, \mathrm{CH}_{3 \mathrm{e}, \mathrm{f}}$ ), $4.16\left(\mathrm{~d}, 4 \mathrm{H}, \mathrm{H}_{1}, 1, \cdots, J \mathrm{~Hz}\right), 7.20\left(\mathrm{~s}, 2 \mathrm{H}, \mathrm{H}_{4,7}\right) ;{ }^{13} \mathrm{C} \mathrm{NMR}$ $\left(100 \mathrm{MHz}, \mathrm{CDCl}_{3}\right) \delta 20.4\left(\mathrm{C}_{\mathrm{a}, \mathrm{b}, \mathrm{d}, \mathrm{d}}\right), 20.5\left(\mathrm{C}_{\mathrm{e}, \mathrm{f}}\right), 29.3\left(\mathrm{C}_{2^{\prime}, 2^{\prime}}\right)$, $56.5\left(\mathrm{C}_{1,1,1}\right), 111.9\left(\mathrm{C}_{4,7}\right), 132.6\left(\mathrm{C}_{8,9}\right), 133.6\left(\mathrm{C}_{5,6}\right), 168.7$ $\left(\mathrm{C}_{2}\right)$; elemental analysis calcd. for $\mathrm{C}_{17} \mathrm{H}_{26} \mathrm{AgClN}_{2}$ : $\mathrm{C} 50.82$, H 6.52, N 6.97\%, found: C 50.9, H 6.9, N 7.2\%.

\section{Antibacterial activity}

\section{Bacterial strains, media and growth conditions}

Bacteria strains used as microorganisms indicator for the antibacterial activity assays were: Micrococcus luteus (M. luteus) LB 14110, Staphylococcus aureus (S. aureus) American Type Culture Collection (ATCC) 6538, Listeria monocytogenes (L. monocytogenes) ATCC 19117, Salmonella Typhimurium ( $S$. Typhimurium) ATCC 14028, Pseudomonas aeruginosa (P. aeruginosa) ATCC 49189 and $E$. coli were obtained from International Culture Collections (ATCC) and local culture collection of the Laboratory of Microorganisms and Biomolecules of the Centre of Biotechnology of Sfax, Tunisia.

These bacterial strains were grown overnight in Luria-Bertani (LB) agar medium $\left(\mathrm{g} \mathrm{L}^{-1}\right)$ : peptone 10; yeast extract 5 and $\mathrm{NaCl} 5$ at $\mathrm{pH} 7.2$ under aerobic conditions and constant agitation $(200 \mathrm{rpm})$ at $30{ }^{\circ} \mathrm{C}$ for M. luteus LB14110 and L. monocytogenes ATCC 19117 and at $37^{\circ} \mathrm{C}$ for $S$. aureus ATCC 6538, S. Typhimurium ATCC 14028 and $P$. aeruginosa ATCC 49189, and then diluted 1:100 in LB media and incubated for $5 \mathrm{~h}$ under constant agitation (200 rpm) at the appropriate temperature.

\section{Agar well diffusion method}

According to Tagg et al..$^{31}$ with certain adjustments, agar well dissemination technique was employed for the assurance of the antimicrobials activity of synthesized compounds. Growth medium $(25 \mathrm{~mL})$ was poured into Petri dishes at $50-70{ }^{\circ} \mathrm{C}$ and it was left to solidify under ultraviolet (UV) light (265 nm wavelength) for $15 \mathrm{~min}$. Subsequently, a sterile cotton swab was dipped into overnight bacterial or yeast suspensions of indicator strains (adjusted to turbidity of $0.5 \mathrm{McF}$ arland standard). An agar plate was inoculated by evenly streaking cotton swab over the agar medium. Then wells with a diameter of $8 \mathrm{~mm}$ were cut in the medium with a sterile cork borer. Stock solutions of the samples were diluted in sterile distilled water to get $500 \mu \mathrm{g} \mathrm{mL} \mathrm{m}^{-1}$ concentrations. The tested samples and controls $(100 \mu \mathrm{L})$ were dispensed into the wells. The plates were incubated at $37{ }^{\circ} \mathrm{C}$ for $24 \mathrm{~h}$. Then the diameters of growth inhibition zones around the wells were measured.

\section{Minimum inhibitory concentration (MIC)}

The minimum inhibitory concentration (MIC) of the synthesized compounds was resolved as per rules M7-A6 $6^{32}$ and M38-P ${ }^{33}$ of National Committee for Clinical Laboratory Standard (NCCLS) ${ }^{34}$ The test was conducted in clean 96well microplates with a final volume in each microplate well of $100 \mu \mathrm{L}$. The synthesized compounds $\left(20 \mathrm{mg} \mathrm{mL}^{-1}\right)$ were appropriately arranged in solution of dimethyl sulfoxide (DMSO)/water $(1 / 9 ; \mathrm{v} / \mathrm{v})$. The inhibitory activity of each synthesized compound was transferred to each well to get a two-fold sequential dilution of the original sample and visible growth after incubation. $25 \mu \mathrm{L}$ of thiazolyl blue tetrazolium bromide (MTT), indicator solution $\left(0.5 \mathrm{mg} \mathrm{mL}^{-1}\right)$ dissolved in clean water were added to the wells and incubated at room temperature for $30 \mathrm{~min}$. This determination was done in triplicate and the results obtained were fundamentally the same. The detailed value is the average of the three tests.

\section{Antioxidant activity: DPPH radical scavenging activity}

Scavenging of 2,2-diphenyl-1-picrylhydrazyl radical (DPPH• examine) is the most generally announced technique for screening antioxidant activity. The methodology includes measurement of decrease in absorbance of DPPH at its assimilation maxima of $517 \mathrm{~nm}$. This test determines the scavenging of stable radical species as indicated by the method of Kirby and Schmidt $^{35}$ with slight alterations. Briefly, synthesized compounds were dissolved in DMSO/water $(1 / 9 ; \mathrm{v} / \mathrm{v})$ and diluted with ultrapure water at different concentrations $\left(1,0.5,0.250,0.125,0.0625,0.03125 \mathrm{mg} \mathrm{mL}^{-1}\right)$. Then, $500 \mu \mathrm{L}$ of a $4 \%(\mathrm{~m} / \mathrm{v})$ solution of DPPH radical in ethanol was mixed with $500 \mu \mathrm{L}$ of samples. The 
mixture was incubated for $30 \mathrm{~min}$ in the dark at room temperature. The scavenging capacity was determined spectrophotometrically by monitoring the decrease in absorbance at $517 \mathrm{~nm}$ against a blank. The percentage of antiradical activity (ArA) had been calculated as follows:

$\operatorname{ArA}(\%)=[($ absorbance of control - absorbance of test sample) / absorbance of control] $\times 100$

\section{Cytotoxicity assay}

Cytotoxicity of compounds was evaluated through MTT test on MDA-MB-231 and MCF7 cells as recently did by Mosmann et al..$^{36}$ To be concise, cells were refined into 96-well plates (Corning, USA) at a thickness of $5 \times 10^{5}$ cells for every well in $200 \mu \mathrm{L}$ medium. After $24 \mathrm{~h}$, cells were treated with various concentrations (10, $5,2.5,1 \mu \mathrm{g} \mathrm{mL}^{-1}$ ) of compounds and further incubated for $48 \mathrm{~h}$ to assess the cytotoxicity of compounds. Toward the finish of the brooding period, $20 \mu \mathrm{L}$ of MTT (3-(4,5-dimethylthiazol-2-yl)-2,5-diphenyl tetrazolium bromide) solution was added to each well. An additional $4 \mathrm{~h}$ incubation at $37{ }^{\circ} \mathrm{C}$ was done, and then the medium was discarded. $\mathrm{MeOH}$ treated cells were utilized as controls. The relative cell viability was determined by reading absorbance at $450 \mathrm{~nm}$ with a microplate reader. The mean optical density (OD, absorbance) of treated and control wells was used to calculate the percentage of cell viability as follows:

Percentage of cell viability $(\%)=(\mathrm{OD}$ treated $/ \mathrm{OD}$ control $)$ $\times 100$

\section{Standard plate count}

Bacterial number in the samples was determined using the standard plate count method. For each dilution series, the sample assumed to have 102 colony-forming unit (CFU) $\mathrm{mL}^{-1}$ was used to inoculate Difco tryptic soy agar (TSA) plates (Fort Richard, Auckland, New Zealand). This assumption was based on the optical density of the most concentrated bacterial solution. For each plate count, a $100-\mu \mathrm{L}$ aliquot of the sample was spread evenly onto a TSA plate and incubated at $37^{\circ} \mathrm{C}$ overnight. For each tested sample, duplicate plate counts were made.

Colony-forming unit (CFU) is a measure of viable bacterial or fungal cells. CFU can be calculated using Miles method ${ }^{37}$ and it is useful to determine the microbiological load and magnitude of infection in blood and other samples.

\section{Results and Discussion}

\section{Preparation of benzimidazolium salts (2a-2j)}

Nitrogen-containing heterocyclic salts have attracted attention in the fields of coordination chemistry due to their metal complexes showing high reactivity as catalyst and biologically agents. In this regards benzimidazolium salts (2a-2j) were synthesized via the two step $N$-alkylation process as depicted in Scheme 1. Compound $\mathbf{1}$ was obtained by $N$-alkylation of benzimidazole with isobutyl bromide (1-bromo-2-methylpropane) in the presence of $\mathrm{KOH}$ in DMSO. The benzimidazolium salts (2a-2j) were prepared by reacting $N$-(isobutyl)-benzimidazole (1) with various aryl halides in DMF at $80^{\circ} \mathrm{C}$ for $24 \mathrm{~h}$ (Scheme 1). The reaction has been monitored following thin layer chromatography, and after this time the formation of salts (2a-2j) has been observed for every target compound. The benzimidazolium salts (2a-2j) were air- and moisture-stable both in the solid state and in solution.

The FTIR, ${ }^{1} \mathrm{H}$ and ${ }^{13} \mathrm{C}$ NMR spectroscopies, and elemental analysis data of the title compound confirm the proposed structure. NMR spectra of all the compounds were analyzed in $d$-CDCl ${ }_{3}$. In the ${ }^{1} \mathrm{H}$ NMR spectra, acidic proton ( $\mathrm{NCHN})$ for benzimidazolium salts $(\mathbf{2} \mathbf{a}-\mathbf{2 j})$ were seen at 12.02, 11.80, 12.02, 11.77, 11.61, 11.79, $12.15,12.27,11.46$ and $11.26 \mathrm{ppm}$, respectively, as a characteristic sharp singlet. In the ${ }^{13} \mathrm{C}$ NMR spectra of $\mathbf{2 a - 2} \mathbf{j}$, the characteristic signals of the imino carbon ( $\mathrm{NCHN}$ ) were detected as typical singlets at 144.1, 142.7, 143.7, 142.8, 144.2, 142.8, 144.1, 144.5, 143.9 and $142.1 \mathrm{ppm}$, respectively. These values are consistent with related literature. ${ }^{38}$ The formation of the benzimidazolium salts were also evidenced by their IR spectra, which showed CN bond absorption at 1437, 1438, 1542, 1558, $1469,1561,1665,1550,1567$ and $1666 \mathrm{~cm}^{-1}$ for the respective $\mathrm{CN}$ bond vibration of $\mathbf{2} \mathbf{a}-\mathbf{2} \mathbf{j}$.

Aromatic protons of benzimidazolium salts $(\mathbf{2} \mathbf{a}-\mathbf{2 j})$ were detected in the range of 6.30-8.02 ppm. $-\mathrm{CH}-$ protons of isobutyl group on all benzimidazolium salts where seen as heptets in the range of 2.25-2.44 ppm. Methylic protons of isobutyl group on benzimidazolium salts (2a-2j) were resonated between 0.98 and 1.04 as doublets. In the ${ }^{1} \mathrm{H}$ NMR spectra of $\mathbf{2} \mathbf{a}-\mathbf{2} \mathbf{j}, \mathrm{NCH}_{2} \mathrm{CH}$ protons appeared as doublet between 4.30 and 4.42 while $\mathrm{NCH}_{2} \mathrm{C}$ protons were detected as typical singlets between 4.87 and 6.95 (Supplementary Information section).

The ${ }^{13} \mathrm{C}$ NMR spectra showed aromatic carbons of benzimidazolium salts $(\mathbf{2} \mathbf{a}-\mathbf{2} \mathbf{j})$ in the range of $105.8-153.8 \mathrm{ppm}$. Terminal carbons of the isobutyl group of all benzimidazolium salts (2a-2j) gave peaks at 19.9, 
<smiles>[R]=[Pt]CC(C)CBr</smiles>

5,6-dimethyl $\underset{80^{\circ} \mathrm{C} / 8 \mathrm{~h}}{\stackrel{\mathrm{KOH} / \mathrm{DMSO}}{\longrightarrow}}$

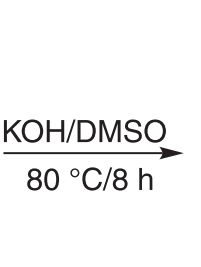

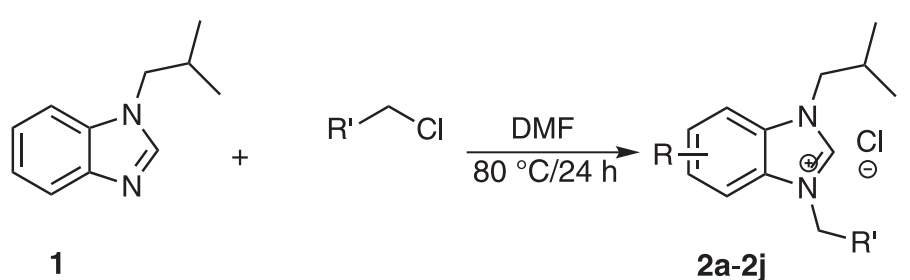

2a-2j<smiles></smiles><smiles></smiles><smiles></smiles><smiles></smiles><smiles>Cc1cc(C)c(Cn2c(=O)n(CC(C)C)c3ccccc32)c(Cl)c1</smiles><smiles></smiles><smiles></smiles><smiles></smiles>

$2 \mathrm{~g}$<smiles>CC(C)Cn1c(=O)n(Cc2c3ccccc3cc3ccccc23)c2ccccc21</smiles><smiles>Cc1cc2c(cc1C)n(CC(C)C)c(=O)n2CC(C)C</smiles>

Scheme 1. Synthesis of benzimidazoles salts $\mathbf{2 a - 2}$ j.

$19.7,19.3,19.9,19.8,19.8,19.9,19.8,19.8$ and 19.8, respectively, while-CH carbons of the isobutyl group were observed at 28.9, 28.7, 28.6, 28.8, 28.9, 28.8, 28.9, 28.8, 28.9 and 28.9, respectively (Supplementary Information section).

The reaction of the benzimidazolium salt with 1 equiv. $\mathrm{Ag}_{2} \mathrm{O}$ in dichloromethane resulted in the silverNHC complex as a crystalline solid. Monitoring of the reaction by ${ }^{1} \mathrm{H} \mathrm{NMR}$ spectroscopy in $d-\mathrm{CDCl}_{3}$ showed that benzimidazolium salts were completely transformed into silver complexes with moderate yields (72-93\%) under argon atmosphere. Synthesis of the $\mathrm{Ag}^{\mathrm{I}}$ complexes were conducted in the absence of light and all complexes were stored in the dark (Scheme 2).

The silver complexes are stable in the air and toward the moisture with good solubility in polar solvents. The successful formation of silver carbene complexes was indicated by the absence of a peak of $\mathrm{NCHN}$ proton in their ${ }^{1} \mathrm{H}$ NMR spectra (Figure 1), further suggested full conversion to silver(I) NHC complexes $(\mathbf{3 a - 3 j})$. In the ${ }^{13} \mathrm{C}$ NMR spectra of $\mathbf{2} \mathbf{a}-\mathbf{2} \mathbf{j}$, the characteristic signals of carbon (NCHN) were seen as singlets between 142.1-144.2 ppm for benzimidazolium salts while for complexes 3a-3j (Figure 2) a signal of carbon (NCN) have shifted greatly downfield region compared to the corresponding benzimidazolium salt $(\mathbf{2} \mathbf{a}-\mathbf{2} \mathbf{j})$ and were observed at $186.7 \mathrm{ppm}$ for complex $\mathbf{3 j}$, however, the rest of carbon signal for the rest of complexes were not observed.

At the same time, formation of the $\mathrm{Ag}^{\mathrm{I}}-\mathrm{NHC}$ complexes (3a-3j) was proven by IR spectra, which showed CN bond vibrations at 1567, 1583, 1450, 1450, $1467,1433,1437,1450,1433,1600 \mathrm{~cm}^{-1}$, respectively. The analytical data are in good agreement with the compositions proposed for all the new compounds we prepared and are summarized in Table 1. 
<smiles></smiles><smiles></smiles><smiles></smiles><smiles></smiles>

3c<smiles></smiles>

3d<smiles></smiles>

$3 g$<smiles></smiles>

3j<smiles></smiles><smiles></smiles>

3i

Scheme 2. Protocol synthesis of $\mathrm{Ag}-\mathrm{NHC} \mathbf{3 a}-\mathbf{3 j}$

Asekunowo et al..$^{39}$ have recently reported the synthesis of a series of mono-carbene silver halides $\left[\mathrm{R}_{2} \mathrm{NHC}\right]-\mathrm{AgCl}$ and have demonstrated the influence of halide ions and the solvent on the structural formulas of $\mathrm{Ag}^{\mathrm{I}}$-NHCs. Similar results have been communicated by Fremont et al..$^{40}$ Ion-pair complexes have been obtained in the reaction of $\mathrm{N}, \mathrm{N}$-dimethylimidazoliumiodide with $\mathrm{Ag}_{2} \mathrm{O}$ in dichloromethane (DCM) ${ }^{41}$ Fluxional behavior between $\left[\mathrm{R}_{2} \mathrm{NHC}\right] \mathrm{AgX}$ and $\left[\left(\mathrm{R}_{2} \mathrm{NHC}\right)_{2}-\mathrm{Ag}\right]+\left[\mathrm{AgX}_{2}\right]-$ species was observed in solution for most of the complexes. ${ }^{42}$ Mechanism of formation of silver $N$-heterocyclic carbenes was reported by Lin et al. ${ }^{43}$ in 2007. According to these results, the monomeric compound $\mathrm{NHC}-\mathrm{Ag}-\mathrm{X}$, in which the two ligands adopt a linear disposition, seems to be the most favorable species in $\mathrm{CH}_{2} \mathrm{Cl}_{2}$ solution.
Biological activities

All the synthesized benzimidazolium salts (2a-2j) and their corresponding silver(I) complexes (3a-3j) were investigated for antibacterial against the both gram $(+) /(-)$ bacteria. The DMSO did not exhibit any antimicrobial activity as reported earlier. ${ }^{44,45}$ The antimicrobial activities of the NHC precursors ( $\mathbf{2} \mathbf{a}-\mathbf{2} \mathbf{j})$ and their corresponding silver complexes (3a-3j) are summarized in Table 2.

Compound $\mathbf{3 i}$ is more active than compounds $\mathbf{3 h}$ and $\mathbf{3 c}$ against the Micrococcus luteus LB 14110. The complexes have shown antibacterial activity to different extents, depending on the nature of the ligand. On comparison with the benzimidazolium salts, the silver complexes have shown enhanced activity. The complexes exhibited enhanced antibacterial activity, which is due to the synergistic effect that increases the lipophilicity of the complexes. Observed 

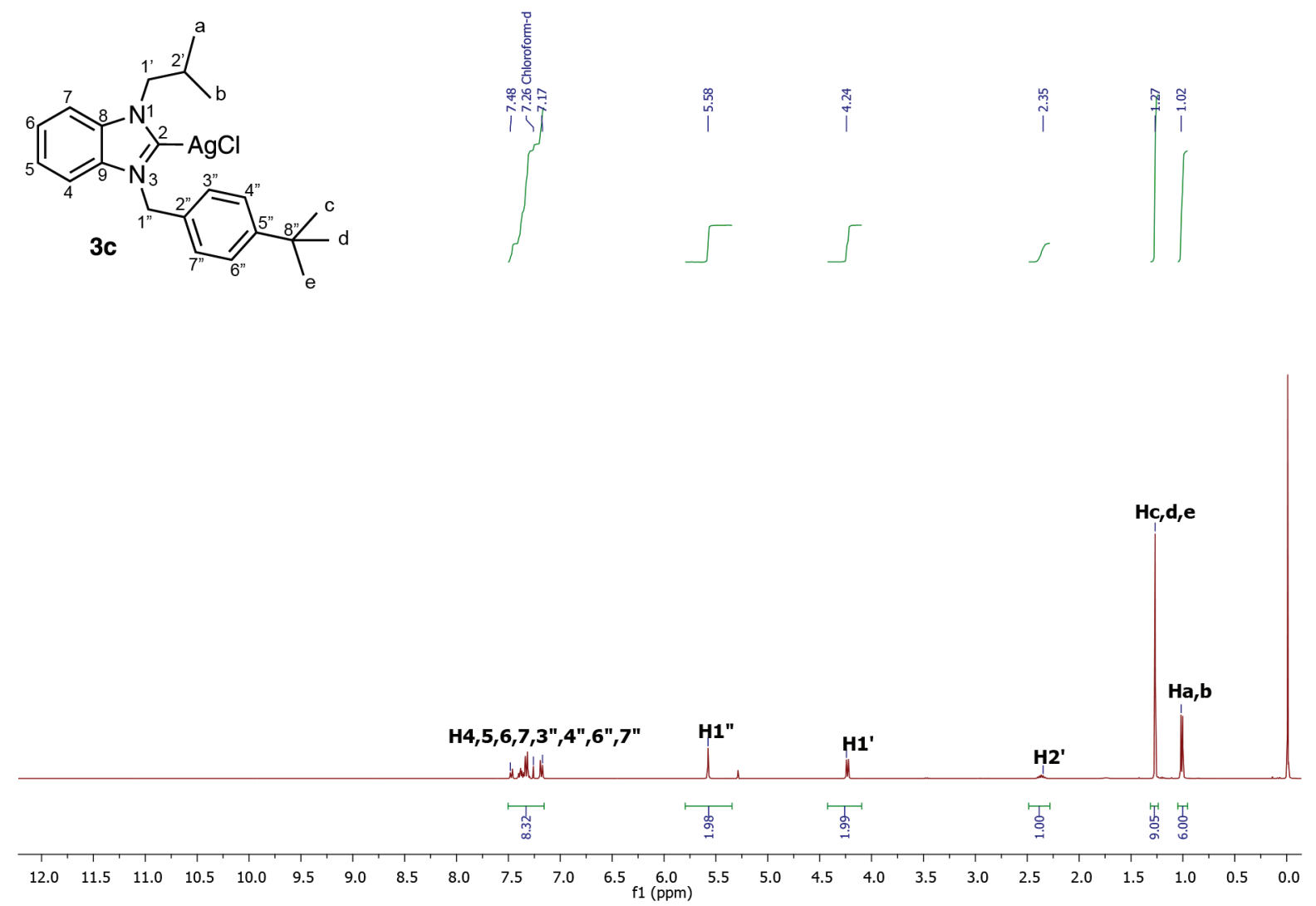

Figure 1. ${ }^{1} \mathrm{H} \mathrm{NMR}$ spectra $\left(400 \mathrm{MHz}, \mathrm{CDCl}_{3}\right)$ of silver complex 3c.
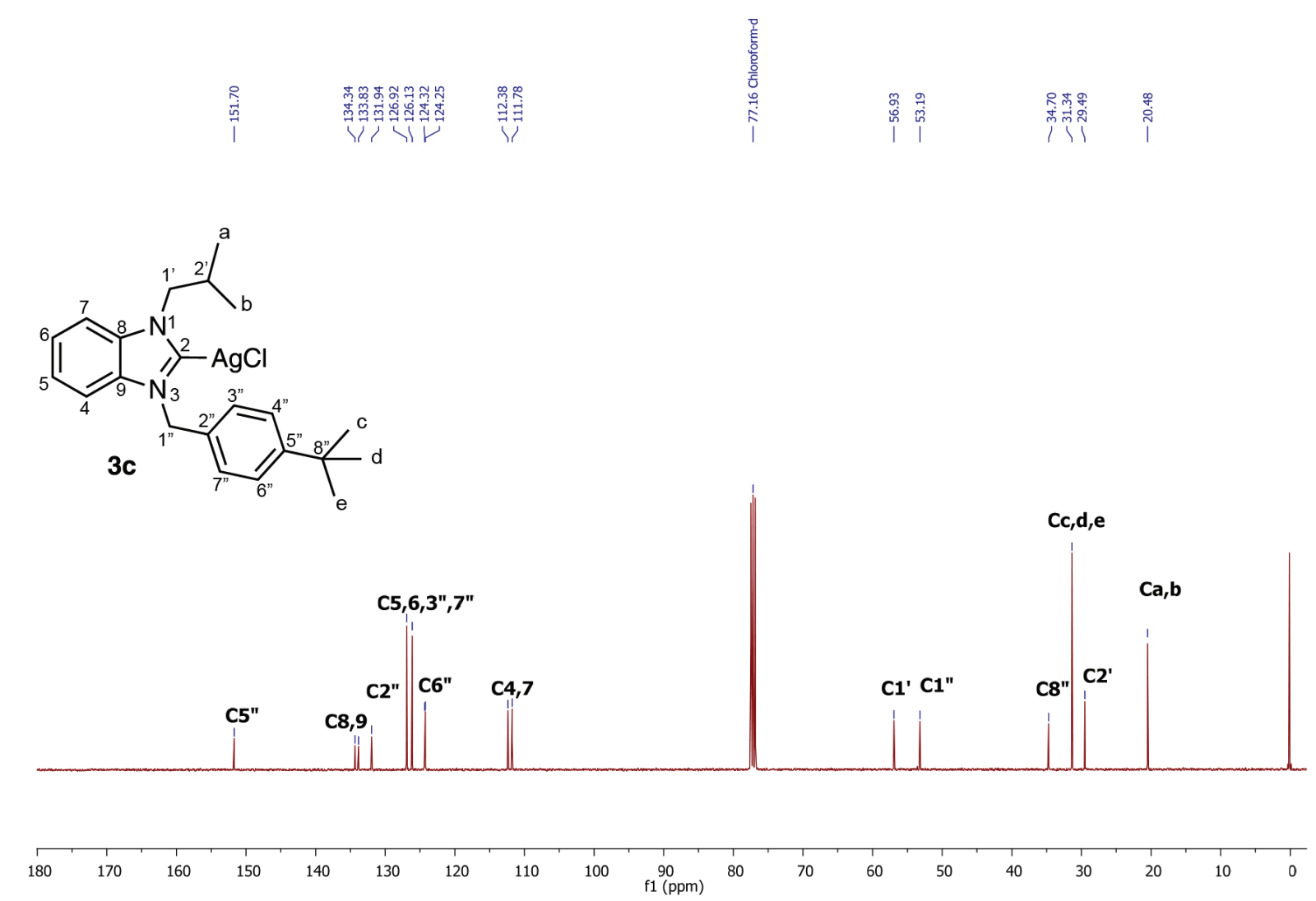

Figure 2. ${ }^{13} \mathrm{C}$ NMR spectra $\left(100 \mathrm{MHz}, \mathrm{CDCl}_{3}\right.$ ) of silver complex $\mathbf{3 c}$. 
Table 1. Physical and spectroscopic properties of new benzimidazolium salts $\mathbf{2} \mathbf{a}-\mathbf{2} \mathbf{j}$ and $\mathrm{Ag}^{\mathrm{I}}$ complexes $\mathbf{3} \mathbf{a}-\mathbf{3} \mathbf{j}$

\begin{tabular}{|c|c|c|c|c|c|c|}
\hline Compound & Molecular formula & Isolated yield / \% & $\mathrm{mp} /{ }^{\circ} \mathrm{C}$ & $v_{(\mathrm{CN})} / \mathrm{cm}^{-1}$ & $\mathrm{H}(2){ }^{1} \mathrm{H}$ NMR / ppm & $\mathrm{C}(2){ }^{13} \mathrm{C} \mathrm{NMR} / \mathrm{ppm}$ \\
\hline $2 \mathbf{a}$ & $\mathrm{C}_{21} \mathrm{H}_{27} \mathrm{ClN}_{2} \mathrm{O}_{3}$ & 93 & 136.2 & 1437 & 12.02 & 144.1 \\
\hline $2 b$ & $\mathrm{C}_{23} \mathrm{H}_{31} \mathrm{ClN}_{2} \mathrm{O}_{3}$ & 92 & 198.2 & 1438 & 11.80 & 142.7 \\
\hline $2 \mathrm{c}$ & $\mathrm{C}_{22} \mathrm{H}_{29} \mathrm{ClN}_{2}$ & 97 & 217.2 & 1542 & 12.02 & 143.7 \\
\hline $2 d$ & $\mathrm{C}_{24} \mathrm{H}_{33} \mathrm{ClN}_{2}$ & 98 & 243.2 & 1558 & 11.77 & 142.8 \\
\hline $2 e$ & $\mathrm{C}_{21} \mathrm{H}_{27} \mathrm{ClN}_{2}$ & 94 & 218.3 & 1469 & 11.61 & 144.2 \\
\hline $2 f$ & $\mathrm{C}_{21} \mathrm{H}_{27} \mathrm{ClN}_{2}$ & 93 & 223.3 & 1561 & 11.79 & 142.8 \\
\hline $2 \mathrm{~g}$ & $\mathrm{C}_{22} \mathrm{H}_{23} \mathrm{ClN}_{2}$ & 89 & 146.4 & 1665 & 12.15 & 144.1 \\
\hline $2 \mathrm{~h}$ & $\mathrm{C}_{26} \mathrm{H}_{25} \mathrm{ClN}_{2}$ & 89 & 278.9 & 1550 & 12.27 & 144.5 \\
\hline $2 \mathbf{i}$ & $\mathrm{C}_{14} \mathrm{H}_{21} \mathrm{ClN}_{2} \mathrm{O}$ & 77 & 108.5 & 1567 & 11.46 & 143.9 \\
\hline $2 \mathrm{j}$ & $\mathrm{C}_{17} \mathrm{H}_{27} \mathrm{ClN}_{2}$ & 87 & 127.9 & 1666 & 11.26 & 142.1 \\
\hline $3 \mathbf{a}$ & $\mathrm{C}_{21} \mathrm{H}_{26} \mathrm{AgClN}_{2} \mathrm{O}_{3}$ & 75 & 136.2 & 1567 & - & not observed \\
\hline $3 \mathbf{b}$ & $\mathrm{C}_{23} \mathrm{H}_{30} \mathrm{AgClN}_{2} \mathrm{O}_{3}$ & 92 & 289.5 & 1583 & - & not observed \\
\hline $3 \mathrm{c}$ & $\mathrm{C}_{22} \mathrm{H}_{28} \mathrm{AgClN}_{2}$ & 78 & 108.6 & 1450 & - & not observed \\
\hline 3d & $\mathrm{C}_{24} \mathrm{H}_{32} \mathrm{AgClN}_{2}$ & 79 & 118.2 & 1450 & - & not observed \\
\hline $3 e$ & $\mathrm{C}_{21} \mathrm{H}_{26} \mathrm{AgClN}_{2}$ & 74 & 194.2 & 1467 & - & not observed \\
\hline $3 f$ & $\mathrm{C}_{21} \mathrm{H}_{26} \mathrm{AgClN}_{2}$ & 93 & 161.2 & 1433 & - & not observed \\
\hline $3 g$ & $\mathrm{C}_{22} \mathrm{H}_{22} \mathrm{AgClN}_{2}$ & 76 & 195.4 & 1437 & - & not observed \\
\hline $3 \mathrm{~h}$ & $\mathrm{C}_{26} \mathrm{H}_{24} \mathrm{AgClN}{ }_{2}$ & 74 & 252.3 & 1450 & - & not observed \\
\hline $3 \mathbf{i}$ & $\mathrm{C}_{14} \mathrm{H}_{20} \mathrm{AgClN}_{2} \mathrm{O}$ & 77 & 188.5 & 1433 & - & not observed \\
\hline $3 \mathbf{j}$ & $\mathrm{C}_{17} \mathrm{H}_{26} \mathrm{AgClN}_{2}$ & 72 & 168.9 & 1600 & - & 168.7 \\
\hline
\end{tabular}

Table 2. Zone of bacterial inhibition of the synthesized salts $\mathbf{2}$ and silver complexes $\mathbf{3}$

\begin{tabular}{|c|c|c|c|c|c|}
\hline \multirow[b]{2}{*}{ Compound } & \multicolumn{5}{|c|}{ Zone of bacterial inhibition / mm } \\
\hline & $\begin{array}{l}\text { Micrococcus luteus } \\
\text { (LB 14110) }\end{array}$ & $\begin{array}{l}\text { Listeria monocytogenes } \\
\text { (ATCC 19117) }\end{array}$ & $\begin{array}{c}\text { Salmonella Typhimurium } \\
\text { (ATCC 14028) }\end{array}$ & $\begin{array}{c}\text { Staphylococcus aureus } \\
\text { (ATCC 6538) }\end{array}$ & Pseudomonas aeruginosa \\
\hline 3a & $21 \pm 0.6$ & $15 \pm 0.5$ & $19 \pm 0.54$ & $17 \pm 0.25$ & $17 \pm 0.13$ \\
\hline $3 \mathbf{b}$ & $23 \pm 0.6$ & $16 \pm 0.6$ & $19 \pm 0.5$ & $18 \pm 0.3$ & $18 \pm 0.14$ \\
\hline $3 \mathbf{c}$ & $36 \pm 0.5$ & $17 \pm 0.2$ & $19 \pm 0.5$ & $19 \pm 0.5$ & $23 \pm 0.2$ \\
\hline 3d & $31 \pm 0.5$ & $15 \pm 0.5$ & $17 \pm 0.10$ & $19 \pm 0.11$ & $17 \pm 0.19$ \\
\hline $3 \mathbf{e}$ & $26 \pm 0.33$ & $23 \pm 0.5$ & $19 \pm 0.5$ & $19 \pm 0.18$ & $21 \pm 0.45$ \\
\hline $3 \mathbf{f}$ & $37 \pm 0.2$ & $17 \pm 0.3$ & $19 \pm 0.5$ & $21 \pm 0.1$ & $21 \pm 0.4$ \\
\hline $3 \mathbf{g}$ & $29 \pm 0.32$ & $17 \pm 0.5$ & $23 \pm 0.44$ & $19 \pm 0.15$ & $23 \pm 0.5$ \\
\hline $3 \mathbf{h}$ & $31 \pm 0.4$ & $17 \pm 0.2$ & $17 \pm 0.2$ & $21 \pm 0.2$ & $19 \pm 0.2$ \\
\hline 3i & $39 \pm 0.2$ & $23 \pm 0.2$ & $23 \pm 0.3$ & $23 \pm 0.2$ & $21 \pm 0.4$ \\
\hline $3 \mathbf{j}$ & $35 \pm 0.44$ & $23 \pm 0.5$ & $23 \pm 0.15$ & $23 \pm 0.3$ & $21 \pm 0.25$ \\
\hline $2 a$ & $21 \pm 0.22$ & - & $22 \pm 0.22$ & $18 \pm 0.05$ & $18 \pm 0.22$ \\
\hline $2 b$ & $19 \pm 0.2$ & $20 \pm 0.2$ & $16 \pm 0.3$ & $20 \pm 0.2$ & $18 \pm 0.2$ \\
\hline $2 c$ & $17 \pm 0.2$ & $18 \pm 0.3$ & $18 \pm 0.22$ & $16 \pm 0.0$ & $16 \pm 0.5$ \\
\hline $2 d$ & $23 \pm 0.2$ & $17 \pm 0.2$ & $15 \pm 0.2$ & $21 \pm 0.2$ & $17 \pm 0.2$ \\
\hline $2 e$ & $19 \pm 0.2$ & $19 \pm 0.22$ & $19 \pm 0.33$ & $19 \pm 0.23$ & $19 \pm 0.22$ \\
\hline $2 f$ & $31 \pm 0.4$ & $23 \pm 0.7$ & $31 \pm 0.4$ & $26 \pm 0.2$ & $19 \pm 0.22$ \\
\hline $2 \mathrm{~g}$ & $23 \pm 0.3$ & $17 \pm 0.4$ & $23 \pm 0.4$ & $19 \pm 0.2$ & $19 \pm 0.2$ \\
\hline $2 h$ & $11 \pm 0.4$ & $15 \pm 0.5$ & $14 \pm 0.10$ & $15 \pm 0.15$ & $17 \pm 0.10$ \\
\hline $2 \mathrm{i}$ & $33 \pm 0.32$ & - & $17 \pm 0.15$ & $19 \pm 0.1$ & $19 \pm 0.15$ \\
\hline $2 \mathbf{j}$ & $21 \pm 0.4$ & $19 \pm 0.5$ & $19 \pm 0.24$ & $19 \pm 0.5$ & $20 \pm 0.16$ \\
\hline Fluconazole & 24 & & & & \\
\hline
\end{tabular}


antibacterial activity of these complexes is comparable to that of previous silver complexes. ${ }^{46}$

\section{MIC determination}

The MIC values of tested silver complexes and their starting material against Listeria monocytogenes ATCC 19117, Salmonella Typhimurium ATCC 14028 and Micrococcus luteus are presented in Table 3.

Table 3. Minimal bacterial inhibitory concentration (MIC) of benzimidazoles salts and silver-NHC complexes

\begin{tabular}{lcc}
\hline Microorganism indicator & Compound & MIC / $\left(\mathrm{mg} \mathrm{mL}^{-1}\right)$ \\
\hline \multirow{2}{*}{ Listeria monocytogenes } & $\mathbf{2 h}$ & 1.25 \\
ATCC 19117 & $\mathbf{2 j}$ & 0.635 \\
& $\mathbf{3 f}$ & 0.0058 \\
& ampicillin & 0.049 \\
\hline Salmonella Typhimurium & $\mathbf{2 h}$ & 1.26 \\
ATCC 14028 & $\mathbf{2 j}$ & 0.041 \\
& $\mathbf{3 f}$ & 0.0034 \\
& ampicillin & 0.635 \\
\hline \multirow{2}{*}{ Micrococcus luteus } & $\mathbf{2 h}$ & 0.3225 \\
& $\mathbf{2 j}$ & 0.3125 \\
& $\mathbf{3 f}$ & 0.0034 \\
& ampicillin & 0.0195 \\
\hline
\end{tabular}

Silver complex 3f showed good activity than that of ampicillin against Micrococcus luteus with an MIC of $0.0034 \mathrm{mg} \mathrm{mL}^{-1}$, while an MIC of $0.0034 \mathrm{mg} \mathrm{mL}^{-1}$ was observed in the case of Salmonella Typhimurium for the silver complex 3f. MICs of other compounds remained within the tested range.

\section{Cytotoxic activities}

The benzimidazolium salts and their corresponding $\mathrm{Ag}^{\mathrm{I}}-\mathrm{NHC}$ complexes were screened colorimetrically using MTT cell assay in two human cancer cell lines, namely MCF7 and MDA-MB-231, to assess their cytotoxicity. The results are presented in Table 4.

As shown in Table 4, the cytotoxicity of $\mathbf{3 i}$ and $\mathbf{3 f}$ was much stronger in MCF7 with half-maximal inhibitory concentration $\left(\mathrm{IC}_{50}\right.$ ) values of 0.63 and $0.69 \mu \mathrm{g} \mathrm{mL} \mathrm{m}^{-1}$, respectively, as compared to their activity on MDA-MB-231 cells. The cytotoxicity of compound $\mathbf{3 j}$ in MCF7 and MDA-MB-231 cells was 1.4 and $3.5 \mu \mathrm{g} \mathrm{mL}^{-1}$, while the $\mathrm{IC}_{50}$ values of compound $\mathbf{2 a}$ were 2.1 and $2.8 \mu \mathrm{g} \mathrm{mL}^{-1}$ against MCF7 and MDA-MB-231, respectively. The compound 2d was inactive against MCF7.
Table 4. Anticancer activity of synthesized of benzimidazoles salts $\mathbf{2} \mathbf{a}-\mathbf{2} \mathbf{j}$ and silver-NHC complexes $\mathbf{3 a - 3} \mathbf{j}$

\begin{tabular}{|c|c|c|}
\hline \multirow[t]{2}{*}{ Compound } & \multicolumn{2}{|c|}{$\begin{array}{l}\text { Anticancer activity } \\
\mathrm{IC}_{50} /\left(\mu \mathrm{g} \mathrm{mL}^{-1}\right)\end{array}$} \\
\hline & MCF7 & MDA-MB-231 \\
\hline $3 \mathbf{a}$ & $4.2 \pm 3.5$ & $4.3 \pm 3.3$ \\
\hline $3 \mathbf{b}$ & $4.1 \pm 3.6$ & $2.6 \pm 4.3$ \\
\hline $3 \mathbf{c}$ & $3.2 \pm 3.1$ & $2.7 \pm 5.9$ \\
\hline 3d & $1.8 \pm 3.1$ & $15 \pm 2.8$ \\
\hline $3 e$ & $4.2 \pm 1.8$ & $0.0 \pm 00$ \\
\hline $3 f$ & $0.69 \pm 3.2$ & $1.94 \pm 2.6$ \\
\hline $3 g$ & $1.4 \pm 4.1$ & $3.4 \pm 2.9$ \\
\hline $3 \mathbf{h}$ & $2.1 \pm 3.2$ & $2.7 \pm 2.9$ \\
\hline $3 \mathbf{i}$ & $0.63 \pm 3.1$ & $1.96 \pm 2.5$ \\
\hline $3 \mathbf{j}$ & $1.4 \pm 4.1$ & $3.5 \pm 2.9$ \\
\hline $2 a$ & $2.1 \pm 3.2$ & $2.8 \pm 2.8$ \\
\hline $2 \mathbf{b}$ & NA & NA \\
\hline $2 c$ & $3.2 \pm 5.9$ & $6.2 \pm 3.2$ \\
\hline $2 d$ & NA & $5.2 \pm 3.1$ \\
\hline $2 e$ & $0.6 \pm 2.9$ & $3.1 \pm 5.9$ \\
\hline $2 f$ & $>100$ & $>100$ \\
\hline $2 \mathrm{~g}$ & $>100$ & $>100$ \\
\hline $2 \mathrm{~h}$ & $>100$ & $>100$ \\
\hline $2 \mathbf{i}$ & $>100$ & $>100$ \\
\hline $2 \mathrm{j}$ & $>100$ & $>100$ \\
\hline Tetracycline $^{\mathrm{a}}$ & NT & NT \\
\hline
\end{tabular}

${ }^{a}$ The concentration was $30 \mu \mathrm{g}$. NA: not active; $\mathrm{IC}_{50}$ : half maximal inhibitory concentration; MCF7 and MDA-MB-231: human cancer cell lines; NT: not tested. Values are mean value \pm standard deviation of three different replicates.

\section{Conclusions}

In conclusion, a series of novel unsymmetrically substituted $N$-heterocyclic carbene precursors and their silver complexes were synthesized and characterized by ${ }^{1} \mathrm{H}$ NMR, ${ }^{13} \mathrm{C}$ NMR, IR and elemental analyses. New silver complexes showed high antibacterial activity compared with the precursors against gram $(+) /(-)$ bacteria and fungi strains. In addition, the silver(I)-NHC complexes $\mathbf{3 i}$ and $\mathbf{3 f}$ showed good antitumor activity against MDA-MB-231, and MCF-7 cell lines. More studies are now in progress including a larger collection of bacteria of different species in order to determine if the antimicrobial activity is species dependent and its possible application in different fields. New biological active Pt or Au-NHC complexes will be prepared with the aim to develop robust cancer 
chemotherapeutic agents. Furthermore, we will test the properties of both transmetallation reaction and catalysis of silver complexes described in this work.

\section{Supplementary Information}

Supplementary information is available free of charge at http://jbcs.sbq.org.br as PDF file.

\section{Acknowledgments}

This work was supported by the Research Supporting Project (RSP2019/75), King Saud University, Riyadh, Saudi Arabia.

\section{Author Contributions}

Ichraf Slimani was responsible for the formal analysis, investigation and methodology; Ahlem ChakchoukMtibaa, Lotfi Mellouli and Lamjed Mansour performed the biological study; Naceur Hamdi, Ismail Ozdemir and Nevin Gürbüz were responsible for the project administration, resources, software, validation, visualization, writing original draft, review and editing.

\section{References}

1. Liu, W.; Gust, R.; Coord. Chem. Rev. 2016, 329, 191.

2. Zou, T.; Ching, A.; Lum, T.; Lok, C. N.; Zhang, J. J.; Che, C. M.; Chem. Soc. Rev. 2015, 44, 8786.

3. Fricker, S. B.; Dalton Trans. 2007, 4903.

4. Narasimhan, B.; Sharma, D.; Kumar, P.; Med. Chem. Res. 2012, $21,269$.

5. Haque, R. A.; Hasanudin, N.; Iqbal, M. A.; Ahmad, A.; Hashim, S.; Majid, A. A.; Ahamed, M. B. K.; J. Coord. Chem. 2013, 66, 3211.

6. Cachoux, F.; Isarno, T.; Wartmann, M.; Altmann, K. H.; ChemBioChem 2006, 7, 54.

7. Narasimhan, B.; Sharma, D.; Kumar, P.; Med. Chem. Res. 2011, 20,1119

8. Asif, M.; Iqbal, M. A.; Hussein, M. A.; Oon, C. E.; Haque, R. A.; Ahamed, M. B. K.; Majid, A. M. S. A.; Eur. J. Med. Chem. 2016, 108, 177.

9. Achar, G.; Shahini, C. R.; Patil, S. A.; Budagumpi, S.; J. Organomet. Chem. 2017, 833, 28.

10. Cheng, C. H.; Chen, D. F.; Song, H. B.; Tang, L. F.; J. Organomet. Chem. 2013, 726, 1.

11. Ozdemir, İ.; Demir, S.; Gunal, S.; Ozdemir, İ.; Arıcı, C.; Ulku, D.; Inorg. Chim. Acta 2010, 363, 3803.

12. Kaloğlu, M.; Kaloğlu, N.; Ozdemir, İ.; Gunal, S.; Ozdemir, İ.; Bioorg. Med. Chem. 2016, 24, 3649.
13. Napoli, M.; Saturnino, C.; Cianciulli, E. I.; Varcamonti, M.; Zanfardino, A.; Tommonaro, G.; Longo, P.; J. Organomet. Chem. 2013, 725, 46.

14. Muenzner, J. K.; Rehm, T.; Biersack, B.; Casini, A.; de Graaf, I. A.; Worawutputtapong, P.; Schobert, R.; J. Med. Chem. 2015, 58,6283 .

15. Streciwilk, W.; Terenzi, A.; Misgeld, R.; Frias, C.; Jones, P. G.; Prokop, A.; Ott, I.; ChemMedChem 2017, 12, 214.

16. Teyssot, M. L.; Jarrousse, A. S.; Chevry, A.; de Haze, A.; Beaudoin, C.; Manin, M.; Gautier, A.; Chem. - Eur. J. 2009, 15,314 .

17. Haque, R. A.; Budagumpi, S.; Choo, S. Y.; Choong, M. K.; Lokesh, B. E.; Sudesh, K.; Appl. Organomet. Chem. 2012, 26, 689.

18. Youn, S.; Yoo, H. J.; Adv. Synth. Catal. 2017, 359, 2176.

19. Frey, G. D.; Schutz, J.; Herdtweck, E.; Herrmann, W. A.; Organometallics 2005, 24, 4416.

20. Sahin, N.; Dusunceli, S. D.; Ozdemir, İ.; Heterocycles 2017, 94, 1506.

21. Haque, R. A.; Salman, A. W.; Budagumpi, S.; Abdullah, A. A. A.; Al-Mudaris, Z. A. A. H.; Majid, A. M. S. A.; Appl. Organomet. Chem. 2013, 27, 465.

22. Iacopetta, D.; Mariconda, A.; Saturnino, C.; Caruso, A.; Palma, G.; Ceramella, J.; Muià, N.; Perri, M.; Sinicropi, M. S.; Caroleo, M. C.; Longo, P.; ChemMedChem 2017, 12, 2054.

23. Saturnino, C.; Barone, I.; Iacopetta, D.; Mariconda, A.; Sinicropi, M. S.; Rosano, C.; Campana, A.; Catalano, S.; Longo, P.; Andò, S.; Future Med. Chem. 2016, 8, 2213.

24. Napoli, M.; Saturnino, C.; Sirignano, E.; Popolo, A.; Pinto, A.; Longo, P.; Eur. J. Med. Chem. 2011, 46, 122.

25. Rana, B. K.; Nandy, A.; Bertolasi, V.; Bielawski, W. C.; Saha, D. K.; Dinda, J.; Organometallics 2014, 33, 2544.

26. Dinda, J.; Nandy, A.; Rana, B. K.; Bertolasi, V.; Saha, D. K.; Bielawskief, W. C.; RSC Adv. 2014, 105, 60776.

27. Garrison, J. C.; Youngs, W. J.; Chem. Rev. 2005, 105, 3978.

28. da Silva, B.; Habibi, M.; Ognier, S.; Schelcher, G.; MostafaviAmjad, J.; Khalesifard, H. R. M.; Bonn, D.; Eur. Phys. J.: Spec. Top. 2016, 225, 707.

29. Varaprasad, K.; Mohan, Y. M.; Vimala, K.; Raju, K. M.; J. Appl. Polym. Sci. 2011, 121, 784.

30. Mirsattari, S. M.; Hammond, R. R.; Sharpe, M. D.; Leung, F. Y.; Young, G. B.; Neurology 2004, 62, 1408.

31. Tagg, J. R.; McGiven, A. R.; Appl. Microbiol. 1971, $21,943$.

32. National Committee for Clinical Laboratory Standards (NCCLS); M7-A6: Methods for Dilution Antimicrobial Susceptibility Tests for Bacteria that Grow Aerobically, $6^{\text {th }}$ ed.; NCCLS: Wayne, 2005.

33. National Committee for Clinical Laboratory Standards (NCCLS); M38-P: Reference Method for Broth Dilution Antifungal Susceptibility Testing of Filamentous Fungi; NCCLS: Wayne, 1998. 
34. Gulluce, M.; Sahin, F.; Sokmen, M.; Ozer, H.; Daferera, D.; Sokmen, A.; Polissiou, M.; Adiguzel, A.; Ozkan, H.; Food Chem. 2007, 103, 1449.

35. Kirby, A. J.; Schmidt, R. J.; J. Ethnopharmacol. 1997, 56, 103.

36. Mosmann, T.; J. Immunol. Methods 1983, 65, 55.

37. Miles, A. A.; Misrna, S. S.; Irwin, J. O.; J. Hyg. 1938, 38, 732.

38. Zonouzi, A.; Mirzazadeh, R.; Safavi, M.; Kabudanian, S. A.; Emami, S.; Foroumadi, A.; Iran. J. Pharm. Res. 2013, 12, 679.

39. Asekunowo, P. O.; Haque, R. A.; Razali, M. R.; Budagumpi, S.; Appl. Organomet. Chem. 2015, 29, 126.

40. Fremont, P.; Scott, N. M.; Stevens, E. D.; Rammnial, T.; Lightbody, O. C.; Macdonald, C. L. B.; Clyburne, J. A. C.; Abernethy, C. D.; Nolan, S. P.; Organometallics 2005, 24, 6301.
41. Chiu, P. L.; Chen, C. Y.; Lee, C. C.; Hsieh, M. H.; Chuang, C. H.; Lee, H. M.; Inorg. Chem. 2006, 45, 2520.

42. Chen, W.; Liu, F.; J. Organomet. Chem. 2003, 673, 5.

43. Lin, I. J. B.; Vasam, C. S.; Comments Inorg. Chem. 2004, 25 , 75 .

44. Hayes, J. M.; Viciano, M.; Peris, E.; Ujaque, G.; Lledós, A.; Organometallics 2007, 26, 6170.

45. Slawson, R. M.; Van Dyke, M. I.; Lee, H.; Trevors, J. T.; Plasmid 1992, 27, 72 .

46. Zhao, G.; Stevens, S. E.; BioMetals 1998, 11, 27.

Submitted: March 5, 2020

Published online: June 3, 2020 